\title{
Job Displacement Insurance and (the Lack of) Consumption-Smoothing
}

\author{
By François Gerard and JoAna Naritomi*
}

We study the spending profile of workers who experience both a positive transitory income shock (lump-sum severance pay) and a negative permanent income shock (layoff). Using de-identified expenditure and employment data from Brazil, we show that workers increase spending at layoff by 35\% despite experiencing a $14 \%$ long-term loss. We find high sensitivity of spending to cash-onhand across consumption categories and for several sources of variation, including predictable income drops. A model with presentbiased workers can rationalize our findings, and highlights the importance of the timing of benefit disbursement for the consumptionsmoothing gains of job displacement insurance policies.

Do consumers smooth consumption? This classic question in economics has received renewed attention in recent years following the availability of new data sources on consumer spending (Gelman et al. 2014, Pistaferri 2015). Across different contexts, this recent body of work has documented a high sensitivity of consumption to positive transitory income shocks (e.g., Shapiro 2005, Parker et al. 2013, Baker and Yannelis 2017, Olafsson and Pagel 2018). In this paper, we study a context in which incentives to smooth are particularly strong. We examine the spending behavior of individuals who receive a lump-sum severance pay - a positive transitory income shock - at the same time as they are laid-off and thus experience a negative permanent income shock (e.g., Stephens 2001, Hendren 2017). Standard economic models with forward-looking agents would typically predict that a large part of this lump-sum should be saved to smooth consumption losses from the negative permanent income shock.

We use de-identified expenditure data linked to matched employee-employer data from Brazil, where laid-off workers are eligible for a government-mandated Severance Pay (SP), in addition to Unemployment Insurance (UI) benefits. Figure 1 shows that these two forms of job displacement insurance have become

* Gerard: Queen Mary University, Mile End Road London E1 4NS UK, f.gerard@qmul.ac.uk. Naritomi: London School of Economics, Houghton Street London WC2A 2AE UK, J.Naritomi@lse.ac.uk. IRB protocol: IRB-AAAQ8869. We would like to thank Alberto Alesina, Oriana Bandiera, Michael Best, Lorenzo Casaburi, Raj Chetty, Mark Dean, Stefano DellaVigna, Itzik Fadlon, John Friedman, Gustavo Gonzaga, Nathan Hendren, Nate Hilger, Ethan Ilzetzki, Yuhta Ishii, Camille Landais, Guilherme Lichand, Attila Lindner, Arash Nekoei, Paul Niehaus, Matthew Notowidigdo, Debraj Ray, Johannes Schmieder, Jesse Shapiro, Johannes Spinnewijn, and many participants at various seminars and conferences. We would also like to thank the International Growth Centre, the National Science Foundation (NSF grant SES-1757105), and STICERD for their financial support. Otávio Braga, Rodrigo Candido, Cristiano Carvalho, Daniel Deibler, Jack Fisher, Dario Fonseca, Samira Noronha, Luiz Superti and a wonderful team of Columbia undergraduates provided outstanding research assistance. 
increasingly common around the world in the last 100 years, and that SP and UI programs often co-exist today (Holzmann et al., 2012).

Our main result is that workers increase spending upon layoff by about $35 \%$ despite experiencing a $14 \%$ long-term loss when they stop receiving any benefits. We interpret these patterns as changes in consumption because they are robust across spending categories, and are not driven by durable goods. Moreover, this high sensitivity of consumer spending to cash-on-hand is present for other sources of variation, including the predictable income drop at the exhaustion of UI benefits (Ganong and Noel, 2019). We show that a simple structural model with presentbiased workers can rationalize our findings. We then use the model to illustrate their implications for disbursement policies, which have been largely overlooked by the UI literature. We show that the insurance value of providing liquidity to workers in a lump-sum fashion at layoff - as with SP programs - can be severely reduced when consumption is over-sensitive to the timing of benefit disbursement.

We begin by describing the empirical setting. We study the state of São Paulo, which is the largest and most developed state of Brazil 1 During the period of analysis, displaced workers were eligible for up to 5 months of UI (at an average replacement rate of 0.75 in our sample), and for a lump-sum payment that combines a government-mandated severance pay from the employer and the permission to withdraw from a forced Severance Savings Account. Because we focus on the way benefits are paid (rather than how they are financed) ${ }^{2}$ we refer to both of these lump-sums under the term Severance Pay (SP) in the paper (combined, they amount to 4.73 times a worker's monthly wage on average in our sample).

We also present our data. In 2007, the state of São Paulo introduced monetary incentives for consumers to ask for receipts (Nota Fiscal Paulista program) in order to reduce the misreporting of sales subject to the state Value Added Tax. To participate, consumers only have to spell out their ID number at the moment of purchase to be included on the receipt, and sellers are required to report receipts to the tax authority, including the consumers' ID number when provided (Naritomi 2019). This is analogous to giving a loyalty card number at the grocery store, which is not very burdensome (Hastings and Shapiro 2018). Perhaps due to low participation costs, the take-up of this program has been substantial. By 2015, more than 18 million people had created online accounts at the tax authority's website to monitor receipts issued with their ID numbers and to claim rewards.

Although the program did not aim at recording individual expenditures, its implementation linked receipts to individual ID numbers, creating a high-frequency record of participants' reported expenditures. We obtained access to these ex-

\footnotetext{
${ }^{1}$ The informal sector remains important in São Paulo. We discuss informality and how it interacts with the formal labor market in section I.A Henceforth, we use employment to refer to formal employment.

${ }^{2}$ Job displacement insurance programs differ in their benefit payout schemes - lump-sum vs. statecontingent - and in their financing schemes - insurance-based vs. savings-based (Parsons, 2016). According to this typology, SP and UI programs are typically insurance-based. Severance Savings Accounts (SSA) - forced savings accounts that workers can withdraw from at separation - are common in Latin American countries. Unemployment Insurance Savings accounts (UISA) - forced savings accounts from which workers can withdraw a fixed amount periodically, contingent on non-employment - remain rare.
} 
penditure data for about 400,000 de-identified workers that were anonymously matched with the Brazilian employee-employer dataset ${ }^{3}$ The matched data allow us to trace individual labor market information, displacement events, and consumer spending from 2010 to 2015 . We also have data on UI benefit claims for these workers from 2010 to 2012 (with exact payment dates). One data limitation is that we do not observe SP, but we have rich data to calculate the lump-sum amount that each worker should receive based on the statutory rules.

We show that displaced workers in our data are relatively comparable to the universe of displaced workers in São Paulo. We also show that our expenditure data provide partial but meaningful coverage for purchases subject to the VAT (it excludes services and housing) and that its coverage is stable across income groups. Importantly, these data include the date and amount of each receipt, and detailed sector information for the seller allowing us to categorize expenditures. Receipts are also reported irrespective of the amount or mode of payment.

Next, we turn to the empirics. First, we present the results of a difference-indifferences analysis in which we estimate changes in expenditures for displaced workers in the 12 months before and after layoff, compared to a control group of workers employed over the whole 25-month period. Trends are similar prior to layoff, but spending increases sharply after layoff for displaced workers, by about $35 \%$. Consumer spending decreases in subsequent months, implying a long-run loss of $17 \%$ for workers who remain non-employed 12 months after layoff, and of $14 \%$ for the overall sample. In present value, the change in consumer spending after layoff (including the transitory increase and the long-term loss) corresponds to a loss of $9 \%$ per month (using a $6 \%$ annual discount rate).

Importantly, workers who are fired for cause are not eligible for any benefits and they experience a sharp and persistent expenditure drop at separation. This suggests that the job displacement insurance benefits are the key driver of the spending profile that we observe for laid-off workers. In addition, workers eligible for higher SP amounts have higher consumption levels in the first months after layoff. These empirical links between spending and benefits - comparing workers who had similar changes in economic condition but different benefits - alleviate concerns that the results are driven by changes in receipt reporting. Moreover, our estimates are not driven by composition effects or differences in time-inhand: the spike at layoff is similar whether workers are reemployed immediately or remain non-employed 12 months after layoff. Finally, the effects are large for various definitions of non-durables, including for sub-categories like food. We thus interpret our findings, at least for non-durables, as consumption responses.

We also exploit other sources of variation in the data. In so doing, we provide further support for the quality of our data as we are able to replicate related

\footnotetext{
${ }^{3}$ The sample of de-identified workers was drawn from users of a smartphone application that offers services to its users based on their account data (see Section I.C. De-identified versions of the data were analyzed in a secure network-isolated data room created for academic research purposes only; no data was shared with the developers of the application, and no original matched data was taken outside the secure data room.
} 
findings from the literature. First, we study changes in non-durable expenditures around UI payment dates. We document a systematic pattern within the UI spell: beneficiaries increase non-durable expenditures in the week after each UI payment by about $20 \%$. "Payday" effects in expenditures have been documented in other contexts (e.g., Olafsson and Pagel 2018), and have been linked to changes in consumption (Shapiro 2005) ${ }^{4}$ Second, we show that workers fail to smooth consumption in anticipation of the predictable drop in income at UI exhaustion. Non-durable expenditures are flat in the months before UI exhaustion, but then drop by $8-13 \%$ after the last UI payment. Ganong and Noel (2019) recently documented a similar finding using consumer spending data from the U.S.5 This finding is even more striking in the context that we study. Displaced workers tend to have limited financial resources at layoff in the U.S. (e.g., Chetty 2008). In contrast, displaced workers in our sample could smooth consumption well beyond UI exhaustion if they dissaved their cash-on-hand at layoff more slowly.

In the last section of the paper, we discuss mechanisms and implications. As in Ganong and Noel (2019), the fact that workers fail to smooth consumption in anticipation of UI exhaustion is a useful result to shed light on the underlying models of behavior. Models with forward-looking but liquidity-constrained agents, which have been used to explain instances of excess sensitivity of consumption to cash-on-hand for positive income shocks, predict that workers would save in anticipation of a predictable drop in income to smooth consumption (Campbell and Hercowitz, 2019, Kaplan and Violante, 2014, Kueng, 2018). In contrast, present bias would generate both a high propensity to consume out of cash-on-hand at layoff and a low propensity to save in anticipation of UI exhaustion ${ }^{6}$

We show this by structurally estimating a simple dynamic model of job-search and consumption with liquidity constraints.7 The model fits key consumption and reemployment patterns in our data with a present-bias parameter of $\widehat{\beta}=.44$ in the naïve case and $\widehat{\beta}=.70$ in the sophisticated case 8 These estimated models perform relatively well out of sample, generating similar marginal propensities to consume as the ones estimated in the empirical analysis for samples that were not used in the estimation.9 9 model with exponential discounting can also fit the data, but with a monthly discount factor that falls outside reasonable

${ }^{4}$ To the best of our knowledge this is the first paper to document "payday" effects for UI benefit.

5 Ganong and Noel (2019) find an increase in spending at layoff for workers who happen to receive their first UI check in the same month as their last paycheck, which is consistent with our main finding. ${ }^{6}$ We discuss in Section IV.F why other models (e.g., savings constraints) unlikely drive our results.

${ }^{7}$ Our model differs from those in DellaVigna et al. (2017) and Ganong and Noel (2019) by allowing for a self-insurance mechanism when non-employed (e.g., added-worker effect, "gig" or informal work).

${ }^{8} \mathrm{~A}$ sophisticated worker knows that savings at layoff will be consumed before reaching UI exhaustion. Her propensity to save is thus lower and the sophisticated model can rationalize the same increase in consumption at layoff with a smaller degree of present bias than the naïve model. See Kuchler and Pagel (n.d.) for a related setting where sophisticated and naïve agents make different savings choices.

${ }^{9}$ One exception is that the models under-estimate the marginal propensity to spend on non-durables for workers receiving smaller SP amounts. Note also that the model in Ganong and Noel (2019), which requires substantial heterogeneity in present bias across workers, would predict very different consumption patterns at layoff for workers reemployed at different points in their unemployment spell because of dynamic selection. This is not the case in our data, which our estimated models accurately predict. 
bounds (monthly $\widehat{\delta}=.69$ ). Moreover, we present survey evidence that is in line with present bias. The majority of UI applicants that we interviewed in São Paulo would not want to receive all UI benefits in a lump-sum fashion at layoff despite the clear financial advantage. Most of them mention the need "to control expenditures" or "to not spend it all at once" as justification, which also suggests some degree of sophistication. Finally, present bias provides a rationale for the existence of forced savings account programs, such as the one that exists in Brazil.

We end by using the estimated models to highlight the role of disbursement policies for job displacement insurance programs. The insurance value of SP programs relies on workers' ability to dissave their lump-sum progressively to smooth consumption. Therefore, it may be lower than that of UI programs, not only because SP does not provide insurance against the risk of remaining nonemployed, but also because consumption is over-sensitive to cash-on-hand.

In addition to the literature on excess sensitivity of consumption to cash-onhand, this paper contributes to a large literature on job displacement insurance. There has been extensive work on UI programs, particularly since Chetty (2006) revisited Baily (1978). In contrast, the literature on SP programs remains more limited, despite their prevalence and the fact that Baily (1978) discussed both types of programs ${ }^{10}$ There is evidence that SP programs distort job-search to a lesser extent than UI programs (Card, Chetty and Weber, 2007), but we know little about their insurance value. For the smaller but growing literature focusing on the context of developing countries (e.g., Gerard and Gonzaga 2020), where SP programs are even more common than UI programs (see Figure 1), our findings also shed new light on the need for insurance for workers laid-off from formal jobs. The long-term loss that we find is comparable to estimates from richer countries, indicating a need for insurance even when informal jobs could serve as self-insurance.

This paper also contributes to the growing literature at the intersection of public economics and behavioral economics. The results help bridge the literatures on UI (e.g., DellaVigna et al. 2017) and household finance (e.g., Olafsson and Pagel 2018), and highlight implications of present bias for policy design (e.g., Lockwood n.d.). That we observe excess sensitivity to an inflow of cash-on-hand even when it is triggered by a negative shock indicates that disbursement policies can affect the consumption-smoothing gains of job displacement insurance policies. Moreover, the model highlights the importance of considering job-search "internalities" when evaluating these policies if workers are present-biased.

Finally, the similarity of our findings around UI exhaustion in Brazil compared to the U.S. evidence in Ganong and Noel (2019) suggests that we document a behavioral pattern of consumption decision that appears stable across societies with quite different labor markets and income levels. An interesting parallel is the

\footnotetext{
${ }^{10}$ There is a large literature on SP programs in labor economics, in which they are studied as creating firing costs. It is easy to show that there is nothing conceptually specific to the benefit payout scheme of SP programs in that respect: perfectly-experienced UI programs would create similar firing costs.
} 
recent evidence on $1 / \mathrm{n}$ repayment of credit card balances, which has been shown to be remarkably similar in Mexico (Ponce, Seira and Zamarripa 2017) and the U.K. (Gathergood et al. 2019). Thus, we seem to be learning that these fundamental features of household decision-making are relatively institution-invariant.

The paper is organized as follows. Section I presents the empirical setting and the data. Sections $[\mathrm{II}$ and $[\mathrm{III}$ contain the empirical results, investigating expenditure profiles around displacement events and UI payment events, respectively. Section [IV] discusses the possible mechanisms behind our findings by estimating a simple structural model, and uses this model to illustrate the implications of our findings for job displacement insurance programs. Section $\mathrm{V}$ concludes.

\section{Institutional background and data}

In this section, we begin by providing relevant institutional background information as well as details on the data used in the empirical analysis.

\section{A. Setting}

The setting of our empirical analysis is the state of São Paulo, the largest state in Brazil. It has a population of 42 million and accounts for $34 \%$ of Brazil's GDP.

A distinctive feature of labor markets in middle-income and developing countries is the substantial share of informal workers. In Brazil, every worker has a working card, and when an employer signs her working card, which is required by law, her hiring is reported to the government (i.e., formal employee). Workers who are not registered with the government include informal employees and selfemployed workers. In São Paulo, a relatively developed state, informal workers still account for about $35 \%$ of private-sector employment 11

There are two main implications of informality for job displacement insurance programs. First, they can only cover displaced formal employees. Second, as the government cannot monitor beneficiaries working informally, their payout schemes can only be made contingent on workers remaining without a formal job. Yet, Gerard and Gonzaga (2020) show that the usual incentive-insurance tradeoff with such programs (Baily, 1978; Chetty, 2006) remains conceptually similar.

\section{B. Job displacement insurance programs}

There are three sources of job displacement insurance benefits in Brazil for workers who are involuntarily laid off from a private-sector formal job.

Unemployment Insurance (UI). Workers with at least six months of job

\footnotetext{
${ }^{11}$ Hiring an employee formally is costly in Brazil. Payroll taxes include $20 \%$ for Social Security as well as $7.8 \%$ for funding various programs. Formal employees are also entitled to the minimum wage, a $13^{\text {th }}$ monthly wage, and a $50 \%$ overtime rate, among other mandated benefits. Firms face severe financial penalties for not complying with labor laws, but the risk of detection is low.
} 
tenure at layoff are eligible for UI benefits after a 30 -day waiting period 12 They must apply for UI within 120 days of the layoff date. UI benefits are then deposited every 30 days at a state bank, Caixa, as long as claimants do not appear in a database where employers report hiring monthly. The potential UI duration depends on workers' total tenure across all formal jobs in the 36 months prior to layoff. They are eligible for three, four, or five monthly UI payments if they have more than 6,12 , or 24 months of tenure, respectively. The benefit level depends on the average wage in the three months prior to layoff and ranges from $100 \%$ to $187 \%$ of the minimum wage (the full schedule is shown in Appendix Figure A1).

FGTS. As in several Latin American countries, there is a Severance Savings Account program in Brazil, the Fundo de Garantia do Tempo de Serviço (FGTS). Every month, employers must deposit $8 \%$ of their workers' monthly wage in an account under each worker's name at the same state bank, Caixa. There is a different account for every employment spell (i.e., every labor contract). The account is highly illiquid, but workers can access the full balance if they are involuntarily laid off.13 The interest rate is notoriously low, barely catching up with inflation. Therefore, displaced workers have strong incentives to withdraw the full balance at layoff. There are also hassle costs if workers delay withdrawal 14

Severance pay. The severance pay includes two components. First, employers must pay a monthly wage to displaced workers as "advance notice" of layoff. Second, employers must pay a "fine" to displaced workers equal to $40 \%$ of the amount deposited in the workers' FGTS account over the employment spell. For clarity, we refer to workers' FGTS balance and severance pay separately in this section. However, as mentioned in the introduction, we refer to both of these lump-sum programs under the term "SP" in the rest of the paper because we focus on the way benefits are paid (rather than how they are financed).

Finally, workers who are fired for cause are not eligible to receive any of the job displacement insurance benefits described above at separation.

\section{Data}

The empirical analysis relies on a combination of administrative datasets.

Formal employment. RAIS (MTE, 2015) is a matched employee-employer dataset that covers the universe of formal employment in Brazil. Every year, all firms must report all workers formally employed at any point during the previous

\footnotetext{
${ }^{12}$ There must also be at least 16 months between a worker's layoff date and the layoff date of her last successful application for UI. Note that the rules described in this section were in place for the whole period covered by our data (2010-2014), but some of these rules changed in more recent years.

${ }^{13}$ The only other events granting access to FGTS accounts are purchases of residential property, serious health shocks, natural disasters, and staying 3 years without a formal job. Any account balance is pensionable, and bequested in case of death. In surveys conducted with UI applicants in São Paulo, only $7 \%$ reported having accessed their FGTS before layoff (see Appendix C and Appendix Table C2). We emphasize that, at layoff, a worker can only access the FGTS balance for the job that they just lost: a worker who quit job A and then was laid off from job B can only access the FGTS balance for job B.

${ }^{14}$ At layoff, workers receive a code for withdrawal from their employer that must be used within 90 days. After that workers can request a new code, but they would incur additional time and hassle costs.
} 
year. It includes the worker ID as well as information on age, race, gender, education, sector of activity, contracted hours, tenure, hiring and separation months, wages, and reason for separation for every employment spell within a year.

UI registry. We use data from the UI registry for the universe of UI beneficiaries from 2010 to 2012 (MTE, 2012). The data include the worker ID, the application date, as well as the date and the benefit amount for all subsequent UI payments.

Lump-sum benefits. One limitation of our data is that we do not observe the FGTS balance or the severance pay. However, because we are able to use RAIS data from 2005 to 2014, we can calculate the statutory job displacement insurance benefits for all workers displaced in 2010-2014 who had at most 72 months of tenure at layoff (90\% of all cases). We also conducted short surveys with 136 UI applicants in São Paulo between July and August 2018 (Gerard and Naritomi, 2018) to get a sense of firms' compliance with their obligations to displaced workers (see Appendix C). Only $2 \%$ of respondents reported any issue in accessing their FGTS balance, $13 \%$ in receiving the $40 \%$ fine, and $16 \%$ in being given their advance notice. Moreover, conditional on firm's compliance, the average amount available lump-sum at layoff was about $489 \%$ of the monthly wage at layoff, which is in line with the statutory amounts that we calculate in our analysis sample (see below). Finally, conditional on having access to these resources, only $4 \%$ reported that they did not (intend to) withdraw the full FGTS balance (see Appendix Table C2).

Expenditures. The main novelty of this paper is that we can anonymously match formal employment and UI data to administrative expenditure data from de-identified receipts that originally specified the consumers' ID numbers. The receipts were generated by the Nota Fiscal Paulista (NFP) program, which was created by the state of São Paulo in 2007 to reduce tax evasion of the statelevel VAT $(I C M S)$ and to foster a culture of tax compliance. In a nutshell, the program created a reward system of tax rebates and monthly lotteries so that final consumers have incentives to ensure that receipts are issued by sellers.

In order to reward consumers, the program introduced the possibility of identifying the consumer's ID number (their $C P F$ ) on each receipt. Sellers are required to report all receipts to the state tax authority, including the consumer's ID number when provided. The tax authority then stores all the transactions for each ID and the consumer can access this information by opening an individual account at the tax authority's website. This account allows the consumer to whistle-blow misreportings by sellers and to collect the monetary rewards.

Naritomi (2019) describes the program in detail and shows that it improved compliance by firms. A key ingredient behind this impact is that consumer takeup was substantial as participation is not very costly; it is analogous to providing a loyalty card number at a grocery store (e.g., Hastings and Shapiro 2018). Receipts already had a field to identify the buyer, which is relevant for tax purposes in the case of business-to-business transactions. For the NFP program, the cashier 
can simply insert the consumer's ID in that same field for final sales ${ }_{15}^{15}$ Moreover, no pre-registration is needed for consumers to start participating. Opening the online account is only necessary to claim the rewards, and consumers can collect all tax rebates retroactively for up to 5 years. In addition, states do not tax personal income in Brazil (it is a federal tax) and their NFP participation cannot be used against consumers for the enforcement of other tax bases. By 2015, more than 18 million people had opened an online account for the program.

Because receipts are linked to individual identifiers, these individual online accounts create a record of participants' expenditures for broad categories of consumer spending. We obtained access to a de-identified version of these data, and we anonymously matched them with data from RAIS and the UI registry for a sample of de-identified accounts through a private company that created a smartphone application offering services to its users based on their account data $\sqrt{16}$ Our matched sample includes about 400,000 de-identified users who participated in the NFP program and had at least one formal employment spell in São Paulo between 2010 and 2014. The expenditure data include all purchases in this period for which these de-identified users provided their ID number. For each purchase, the data include the date, the total value, the number of items, and the 7 -digit sector of activity code of the seller $(C N A E)$, which allows us to classify expenditures in categories such as durables, non-durables, groceries, etc ${ }^{17}$

By design, the expenditure data only include purchases for which workers in our sample chose to provide their ID number, but the data are not restricted by purchases' value or mode of payment (they include cash transactions). We show below that they provide meaningful coverage for purchases of goods (i.e., the VAT base, excluding services and rent). We also show that displaced formal workers in our data and in São Paulo as a whole are relatively comparable.

\section{Description of the analysis sample}

In this section, we present summary statistics for our main analysis sample to describe the empirical setting. We also evaluate the representativity of our analysis sample by comparing it to a benchmark sample, drawn randomly from the universe of displaced formal workers in São Paulo.

Our main analysis sample is constructed as follows. From RAIS, we select all full-time private-sector formal employees in São Paulo who were laid off between 2011 and 2013. This window allows us to have expenditure and employment data for at least one year before and after layoff for all workers with expenditure data. We further restrict attention to workers who had at least 12 months of tenure at layoff, such that they have some prior attachment to the formal labor force, and at

\footnotetext{
${ }^{15}$ We highlight this field on a copy of a VAT receipt from São Paulo in Appendix Figure B1.

${ }^{16}$ We accessed de-identified versions of the data in a secure network-isolated data room created for academic research purposes only (Anonymous firm, 2017); no data was shared with the developers of the application, and no original matched data was taken outside the secure data room.

${ }^{17}$ For instance, CNAEs 4722-9/01 and 4753-9/00 are retail of meat and of household appliances, video and photo equipment. Appendix B explains how we mapped CNAEs into spending categories.
} 
most 72 months of tenure, such that we can calculate their statutory SP amount and FGTS balance at layoff. We obtain a sample of 77,892 layoff events after keeping workers who had positive purchases in the expenditure data both before and after the 25-month window centered around layoff (to make sure that they were NFP participants throughout the period). We obtain a benchmark sample of 156,110 layoff events by selecting $5 \%$ of the overall RAIS sample at random.

Table 1 displays descriptive statistics of variables at or before layoff in the two samples, as well as their difference. All the differences are statistically significant at the $5 \%$ level, but they are modest in size. The first number that stands out is that our analysis takes place in an urban setting: almost all workers were employed in an urban municipality (about half in the metropolitan area of the city of São Paulo), and the shares were only slightly larger in the analysis sample (97.4\% vs. $97.1 \%)$. The shares of females (43.6\% vs. $39.1 \%)$ and white workers ( $70.3 \%$ vs. $69.4 \%)$ were also larger in the analysis sample and the average worker was slightly older (32.82 years vs. 32.55 years). The most notable difference is that education levels were higher in the analysis sample, e.g., the share of workers with a high school degree was $7.5 p p$ higher $(72.8 \%$ vs. $65.3 \%)$. Accordingly, workers were "positively selected," i.e., they had more tenure (30.20 months vs. 29.24 months) and a higher monthly wage ( $\mathrm{R} \$ 1341$ vs. $\mathrm{R} \$ 1280)$ at layoff, and thus a lower UI replacement rate $(75.1 \%$ vs. $76.6 \%){ }^{18}$ These differences are relatively small, but we take them into account in a robustness analysis below 19

Figure $2 \mathrm{a}$ shows that the average statutory job displacement insurance benefits are comparable in the two samples, although the lump-sum values are slightly lower in the benchmark sample (this is consistent with the tenure and wage differences in Table 1). The average replacement rates (benefit/wage) for the FGTS balance, the SP amount, and the monthly UI benefit are $245 \%, 227 \%$, and $75 \%$ in the analysis sample, respectively (see Table 1 ). Figures $2 \mathrm{~b}-2 \mathrm{~d}$ show that the two samples are also comparable in terms of UI take up and reemployment outcomes.

The patterns in Figures $2 \mathrm{~b}-2 \mathrm{~d}$ provide useful background information on displaced formal workers in São Paulo. Figure $2 \mathrm{~b}$ displays the share drawing UI benefits in each month after layoff. Because of the 30-day waiting period, the share is nil in the month of layoff. It remains small in the following month (about $20 \%$ ), but it increases quickly afterward and peaks in month 3 after layoff. Overall, the UI takeup rate (i.e., the share drawing any UI benefit) is $76.8 \%$ in the analysis sample ( $80.2 \%$ in the benchmark sample). The share drawing UI benefits remains stable from months 2 to 5 . It then decreases quickly in months 6 to 8 , which is consistent with the fact that most UI takers exhaust their potential

\footnotetext{
${ }^{18}$ We focus on the wage value that becomes cash-on-hand ("net monthly wage") by deducting the statutory values of personal income tax and social security contributions. We then use net wages to calculate all replacement rates (UI benefit/wage, SP amount/wage, FGTS balance/wage) in Table 1. All monetary values in the paper are in $\mathrm{R} \$ 2010$ (US $\$ 1 \simeq \mathrm{R} \$ 2$ in 2010) using the IPCA index (IBGE, 2016).

${ }^{19} \mathrm{~A}$ likely reason why workers are relatively comparable between the analysis sample and the benchmark sample is that a large share of adults in São Paulo who are attached to the formal labor market have smartphones (e.g., $91 \%$ in our survey of UI applicants; see Appendix Table C1).
} 
UI duration in Brazil (Gerard and Gonzaga, 2020). Workers in our samples are eligible for 4 to 5 months of UI, and the average UI duration reaches 4.22 months among UI takers in the analysis sample (4.27 months in the benchmark sample) 20

Most workers exhaust their UI benefits because formal reemployment rates are low after layoff, as shown in Figure 2k. The hazard rate of formal reemployment is slightly higher in the analysis sample, explaining the lower UI takeup rate and average UI duration in Figure 2 $\mathrm{b}$. However, the hazard rate is low in both samples. As a result, Figure $2 \mathrm{~d}$ shows that about $75 \%$ of displaced workers in the analysis sample ( $80 \%$ in the benchmark sample) remain without a formal job at the beginning of month 5 when workers start reaching the end of their potential UI duration. The hazard rate starts increasing around the same time, peaking in months 6 and 7, which suggests that UI incentives depress formal reemployment. Yet, the hazard rate remains relatively low even after UI exhaustion, when UI does not generate disincentives to search for a formal job anymore. Consequently, a sizable share of workers remains without a formal job 12 months after layoff (30\% in the analysis sample and $40 \%$ in the benchmark sample).

\section{E. Coverage of the expenditure data}

Our source of consumer spending data is based on VAT receipts in São Paulo linked to individual IDs as explained in Section I.C. The receipts cover a rich set of expenditure categories (e.g., groceries, restaurants, clothing, and other nondurable and durable spending) and include any payment method. However, the VAT is only levied on goods, so the data does not cover VAT-excluded items, such as services and housing. Moreover, among VAT covered purchases, we unlikely observe all expenditures because consumers voluntarily provide their ID number to be inserted in the receipt. Also, the consumer may not provide her ID number for all her purchases and she may not be making all the household's purchases ${ }^{21}$

Although incomplete, the last row in Table 1 already presents evidence that the data cover a sizable share of consumers' purchases of goods. The mean monthly expenditure in our data in the 12 months before layoff is $34.3 \%$ of the mean monthly wage prior to layoff, despite excluding services and rental costs. Yet, it is key that the coverage of the data remains constant following relevant changes in the economic environment, such as income shocks and employment changes. Otherwise, we would confound changes in expenditures and changes in coverage. This is difficult to directly evaluate in our case because there is no other panel dataset of expenditures in Brazil to which we could benchmark our data. However, we are able to validate our data with a number of empirical exercises.

\footnotetext{
${ }^{20}$ The samples in Figure 2 $\mathrm{b}$ are restricted to workers laid off in 2011 such that we have data for their full UI spell. Figures 2a, 2, and $2 \mathrm{~d}$ remain similar with this restriction (see Appendix Figure A2).

${ }^{21}$ The NFP program creates incentives for households to provide the same ID number when making a purchase, independently of the identity of the consumer, as it gives participants one lottery ticket for each $\mathrm{R} \$ 50$ in total reported purchases. In our survey of UI applicants, $62 \%$ of respondents who participate in the NFP program report using a unique ID number for all the household's purchases.
} 
Figure 3 a first shows that the coverage of our data is relatively constant across wage levels when compared to data from the 2009-2010 National Household Budget Survey (IBGE, 2011), which was conducted by the Brazilian Census Bureau (IBGE) and is a representative cross-section of households across Brazilian states (we use the São Paulo state sample). It displays the ratio of average expenditures as measured in our data and average household expenditures in the survey data, by wage decile for workers formally employed at the time of the interview (survey data) and on December 31st (our data) ${ }^{22}$ We restrict attention to spending categories that are covered in both datasets (i.e., the purchase of goods). We define the deciles based on the wage distribution in the survey data. We then estimate average spending in each decile for each dataset separately before taking their ratio, reweighing our data to match the survey data on observables recorded in both datasets ${ }^{23}$ Confidence intervals are calculated by the delta method.

Figure 3 a shows that there is no systematic change in the ratio across deciles, indicating that the coverage of our data is relatively constant across wage levels. It also shows that our data capture a sizable share of household expenditures, namely $26 \%$ of average expenditures in the survey data for comparable spending categories. If we consider all spending categories (e.g., including housing and services for the survey data), average expenditures in our data account for $16 \%$ of average expenditures in the survey data (see Appendix Figure B2).

Ideally, we would also show that the coverage remains constant over the panel dimension of our data, in particular across employment and income shocks. What we can do in this regard with the data in hand is to compare consumer spending responses to income changes observed in our data with evidence from other contexts. For this purpose, Figure $3 \mathrm{~b}$ displays a binscatter of the correlation between $\Delta \log ($ expenditure $)$ and $\Delta \log ($ wage $)$ in our data. ${ }^{24}$ The correlation of .269 is comparable to the correlation between changes in spending and labor income in Baker (2018), who uses data from a personal finance website in the U.S.

A potential concern that the evidence above cannot address directly is that the likelihood that workers provide their ID number when making purchases might change after layoff. We note that changes in time availability or other resources at layoff should not necessarily affect the propensity to ask for receipts as participation costs are relatively low. Nonetheless, in the next sections, we provide further evidence that our findings are unlikely driven by changes in data coverage. For instance, we document various pieces of evidence that expenditures follow variations in cash-on-hand, and not other changes experienced by workers. We find very different patterns in consumer spending after displacement for workers with

\footnotetext{
${ }^{22}$ In our data, we look at the 2010-2011 period, which is the closest to the 2009-2010 survey period.

${ }^{23}$ Age quartiles and dummy variables for being white, having a high school degree, and being female.

${ }^{24}$ We exploit change in wages for workers who switch firms between 2010 and 2014, restricting attention to those who were employed on December $31^{\text {st }}$ in at least two consecutive years in the origin and destination firm (RAIS has better wage data for the month of December in each year). These are sizable income changes that we can measure in our data and that are not purely transitory. We then regress $\Delta_{t-1}^{t+1} \log ($ expenditure $)$ on $\Delta_{t-1}^{t+1} \log ($ wage $)$ and year fixed effects, where $t$ is the first year in the new job
} 
different benefit eligibility but similar changes in time availability (see Figure 4 comparing laid-off vs. fired workers). We also show that workers with similar benefit eligibility but different changes in time availability display very similar spending patterns at layoff (see Figure 5 for workers reemployed immediately). Finally, we document clear changes in consumer spending following changes in income unrelated to time availability, e.g., differences in the SP amount at layoff and incomes changes after UI benefit payment dates and UI exhaustion.

Another potential concern is that changes in the share of household purchases made by workers after layoff may affect the patterns that we observe. We find that our main results are very similar for men and women, which is useful to the extent that the proportion of household purchases made by workers is less likely to vary for women than for men in the Brazilian context. Finally, increases in the share of purchases made in informal stores after layoff might lead us to overestimate the long-term loss. However, we find that it is even larger for pharmacy expenditures, a category for which the informality margin is essentially irrelevant.

Together, the evidence in Figure 3 and the results in the next sections indicate that our data capture meaningful effects of labor market events on consumer spending rather than changes in data coverage. The fact that we also replicate specific empirical findings from the literature in the next sections, such as payday effects (Olafsson and Pagel, 2018) and the drop in consumer spending at UI exhaustion (Ganong and Noel, 2019), further supports the quality of our data.

\section{Expenditure profile around displacement}

We study changes in consumer spending after layoff by conducting a number of event studies around the month of dismissal. Specifically, we use a differencein-differences (DD) research design in which we estimate changes in consumer spending for displaced workers in the 12 months before and after layoff, compared to a control group of workers employed over the whole 25 -month period. As a reminder, we now refer to all resources made available to workers in a lump-sum fashion at layoff under the term "SP" (or "SP amount"). We also use the term employment to refer to formal employment.

\section{A. Empirical strategy}

We estimate changes in expenditures in the 12 months before and after layoff for the sample of displaced workers described in Section I.D (see column 1 in Table 1 ). We use a control group of workers employed over the whole 25-month period to net out overall trends in the data in a difference-in-differences specification:

$$
y_{i t k}=\alpha_{i}+\alpha_{k}+\alpha_{t}+\sum_{k \neq k^{\prime}} \beta_{k} \cdot \text { Treat }_{i}+\epsilon_{i t k}
$$

where $\alpha_{i}$ 's are worker-event fixed effects (a fixed effect for each layoff if the same worker experiences several events), $\alpha_{k}$ 's are event time dummies (months to/from 
layoff; $k \in[-12,12]$ and negative values correspond to pre-event months), and $\alpha_{t}$ 's are calendar time fixed effects. The coefficients $\beta_{k}$ 's trace differential changes in consumer spending $y_{i k t}$ for displaced workers in the months around layoff compared to a reference month $\left(k^{\prime}=-6\right)$. We cluster standard errors by worker.

We construct the control group as follows. We create worker-month pairs for "placebo" displacement events by selecting months between 2011 and 2013 for which workers are observed continuously employed in a full-time private-sector job in the 25-month period centered around those months ${ }^{25}$ We are left with a control group of 220,160 placebo displacement events in 2011-2013. There can be several worker-month pairs for a given employment spell in the remaining sample. In that case, we randomly select one worker-month pair per year. Workers can thus serve as placebo displaced workers at most once a year, but they can do so in multiple years, which is a main reason why we use worker-event fixed effects.

Columns (1), (4), and (5) in Table 1 show that our treatment and control groups differ systematically. For instance, control workers had higher wages, more tenure, and higher expenditure levels before the (placebo) layoff. Given these differences, we reweight the observations in the control group in all our regressions such that it compares better to the treatment group in terms of wage (and thus UI benefit), total SP amount, and average expenditure prior to layoff (over $k=-12, \ldots,-6){ }^{26}$ Unless mentioned otherwise, we always follow the same reweighing strategy in the rest of the paper for all samples used in our regressions (e.g., fired workers or subsets of the treatment group). We estimate regressions in levels but present our results in relative changes by dividing the $\widehat{\beta_{k}}$ 's coefficients by the mean in the treatment group in the reference month.

\section{B. Main results}

Laid-off event. Figure 4 a presents our first DD results. The black line displays estimates using all treatment and controls units (unconditional sample). The grey line displays estimates restricting the treatment group to displaced workers who remain non-employed in each month after layoff (survival sample; see, e.g., Kolsrud et al. 2018). The whole treatment group is included prior to layoff (the black and grey lines coincide), but workers exit the survival sample as soon as they are reemployed (the share of workers that remain in the sample each month matches the survival rate in Figure $2 \mathrm{~d}$ ). This sample captures the workers who would remain eligible for UI benefits, which are contingent on non-employment 27

\footnotetext{
${ }^{25}$ Similarly to the layoff sample, we restrict attention to pairs for which workers have at most 72 months of tenure, such that we can calculate their placebo statutory job displacement insurance benefits as if they were laid off in that month. We also require workers to have positive expenditures both before and after the 25-month period to make sure that they were consistent participants throughout the period.

${ }^{26}$ We define 250 cells using quintiles of the wage, quintiles of the SP amount, and deciles of the mean expenditure in months $k=-12, \ldots,-6$ in the treatment group. We then reweight observations such that the cells have the same weight in the control group as in the treatment group (see, e.g., Naritomi 2019).

${ }^{27}$ Given that the survival sample changes over time, we divide the $\widehat{\beta_{k}}$ 's coefficients by the mean in the reference month for workers who still belong to the sample in month $k$. We also re-weight the observations
} 
Estimates are very close to 0 for most of the pre-layoff period, supporting our common-trend assumption ${ }^{28}$ They become slightly negative in the two months before layoff $(-1.3 \%$ and $-3.3 \%$, respectively). We do not focus on this pattern because it is not always robust across samples and categories of expenditures 29

The most striking pattern is that total expenditures increase by $31.4 \%$ and $37.7 \%$ in the month of layoff and in the subsequent month, respectively. Estimates decrease quickly but remains positive in months 2 and 3 after layoff. They are negative and more stable in months 4 and 5 , at around $-4 \%$. They then decrease again faster in months 6 to 8, when workers exhaust their UI benefits. Estimates also start diverging between the unconditional and the survival samples in those months. Hazard rates are higher in months 6 to 8 (see Figure2 2), increasing more rapidly the share of the unconditional sample that is reemployed, while workers in the survival sample remain by definition non-employed. Estimates are stable in months 8 to 12 and imply a long-run loss 12 months after layoff of $-14.2 \%$ and $-17.4 \%$ in the unconditional and survival samples, respectively.

In present value, the overall change in consumer spending after layoff (including the spike at layoff and the long-term loss) corresponds to a loss of $9 \%$ per month 30

Laid-off vs. fired. Figure $4 \mathrm{~b}$ compares DD results for laid-off workers and for workers who were fired for cause (fired henceforth), and were therefore not eligible for job displacement insurance at separation. The control group remains the same in both cases. We construct the sample of fired workers following the same steps as for laid-off workers. We obtain 4,041 firing events, which is relatively small, so estimates are less precise. This is why we only present results for the unconditional sample in Figure $4 \mathrm{~b}$ (see Appendix Figure A4 for the survival sample).

Figure $4 \mathrm{~b}$ shows that estimates are close to 0 for fired workers prior to displacement, as in the case of laid-off workers. Upon displacement, however, the estimates clearly diverge: fired workers experience a drop in consumer spending that reaches $-26 \%$ in month 1 . The sharp difference in spending profiles between the two groups indicates that job displacement insurance benefits are driving the spending patterns at layoff. In particular, the increase in spending at the displacement event among laid-off workers is unlikely due to a complementarity between leisure (i.e., time) and recorded expenditures in our data since the same should be true for fired workers 31 The estimates for fired workers remain low in

\footnotetext{
in the survival sample such that the 250 cells (wage $\times$ total SP amount $\times$ pre-layoff expenditure) have the same weight in each month as in the unconditional sample (and the control group).

${ }^{28}$ Appendix Figure A3a shows the average monthly expenditure level in each of the 25 months around the event for the treatment and control groups separately.

${ }^{29}$ Workers' wages may grow slower just before layoff, they may be less likely to work overtime, or they may postpone some expenditures until they receive their SP amount. In our survey of UI applicants, $13 \%$ experienced a slower wage growth in the months before layoff (see Appendix Table C2).

${ }^{30}$ Using a similar specification, we find that the long-term loss persists in months 13 to 24 after layoff. We then assume that it would persist until at least 5 years after layoff (we cannot track workers for that long because of data constraints) and we compute the net present value of the change in spending over the 5-year period after layoff using the unconditional sample and a $6 \%$ annual discount rate.

${ }^{31}$ Such complementarity could arise, e.g., through an increase in the likelihood that a worker provides her ID number when making purchases, in the proportion of household purchases made by the worker, or in the time available to make purchases.
} 
the following months and below the estimates for laid-off workers, even though the share of workers reemployed is higher among fired than laid-off workers (see Appendix Figure A8), which is consistent with UI job-search disincentives.

Heterogeneity by time of reemployment. Figure 5 displays results from applying the same research design as in Figure 4 a to different subsets of the treatment group. The black lines in panels (a)-(d) highlight the spending profile of workers reemployed in months $0,4,8$, and 12 after layoff, respectively (we use the full control group in each case). The point estimates for the other three groups are also plotted in grey in all graphs to facilitate the comparison between the group that we highlight and workers reemployed in different months.

Figure 5 presents three important findings. First, all groups of workers experience a sharp and significant increase in expenditures at layoff. In particular, we find the same increase in spending for workers reemployed immediately. This result provides further support to the argument that the increase in spending at layoff is unlikely due to a complementarity between leisure (i.e., time) and recorded expenditures in our data. Second, workers reemployed immediately are the only group that does not experience a long-run loss. A likely reason for the long-run loss in the other samples is that reemployed workers experience a $10.1 \%$ wage loss compared to before layoff on average ${ }^{32}$ Third, Figures $5 \mathrm{~b}$ and $5 \mathrm{k}$ show that expenditure levels increase in the month following reemployment; the effect is sharper in Figure 5c because workers have run out of benefits by month 8 . To complement this finding, we present results from an event analysis centered around reemployment in Appendix Figure A5: spending increases by about $5 \%$ if we use workers reemployed in months 0 to 10 and by about $10 \%$ if we focus on those reemployed after UI benefits have been exhausted. Thus, the consumer spending pattern appears to follow cash-on hand across all groups of workers.

Robustness checks. We conduct a number of robustness checks. Figure 5 already indicates that the patterns in Figure 4 a are not driven by composition effects, i.e., workers reemployed quickly driving the spike in consumer spending at layoff and those reemployed late driving the long-term loss. Appendix Figure A3b show that these patterns are also present for workers not reemployed by month 12 after layoff. Appendix Figure A3c show that we find similar patterns for the median, so the results in Figure $4 a$ are not driven by outliers 33 In addition, we obtain similar patterns if we restrict the treatment group to workers laid off from a downsizing firm, which lost at least $30 \%$ of its workforce in the layoff year (see Appendix Figure A3d). This addresses possible concerns of endogenous layoffs,

\footnotetext{
${ }^{32}$ We use the specification: $\log$ Wage $_{i t k}=\alpha_{i}+\alpha_{t}+\beta \cdot$ Treat $_{i}+\gamma \cdot$ Treat $_{i} \cdot$ After $_{k}+\epsilon_{i t}$, where $\operatorname{LogWage}_{i t}$ is the logarithm of the average wage in the year before $\left(\right.$ After $\left._{k}=0\right)$ or after $\left(\right.$ After $\left._{k}=1\right)$ displacement. The regression sample includes one observation per year before and after displacement, per worker in the control group and per worker reemployed by month 12 in the treatment group.

${ }^{33}$ The results for the median also address possible concerns that our findings might be due to displaced workers making purchases in order to invest in a small business at layoff (e.g., buying goods for resale). Only $4 \%$ of respondents in our survey of UI applicants report planning to use the lump-sum amounts they receive upon layoff to invest in a business (see Appendix Table C3). So any such behavior is likely concentrated in a small subset of displaced workers, and is thus less likely to affect the median results.
} 
e.g., of workers triggering their layoff to access their FGTS balance. Finally, we find similar results if we reweight both treatment and control groups to match the distribution of observables in the benchmark sample described in Table 1 (see Appendix Figure A3e) ${ }^{34}$ Thus, the differences between the analysis sample and the benchmark sample documented in Table 1 do not seem to affect the results.

In sum, we find a large increase in expenditures at layoff despite a sizable longrun loss. The long-run loss is comparable to existing estimates in the literature (e.g., Ganong and Noel 2019 for the U.S.). In contrast, existing studies typically find a drop in expenditures at layoff, but they do not study a context where workers receive lump-sum job displacement insurance benefits. Comparing the average increase in expenditures to the average increase in financial resources, and considering that we observe about $26 \%$ of household expenditures on goods (see Figure 3a), we obtain a marginal propensity to spend on goods of .47 over the first three months after layoff. This figure is likely a lower bound as we use the statutory SP amounts and our survey of UI applicants indicates that firms' compliance with their obligations to displaced workers is high but not perfect.

\section{Heterogeneity by expenditure category}

We interpret the findings in Figure $4 \mathrm{a}$ as capturing changes in consumption because these findings are robust across expenditure categories and, as we show here, are not driven by the purchase of durable goods.

Figure 6 a displays the composition of average expenditure prior to layoff (over $k=-12, \ldots,-6)$ in the treatment group, the main categories being food $(40.6 \%$; mostly groceries), other non-durables (39.8\%; mostly personal goods), and durables $(11.2 \%)^{35}$ Thus, non-durables constitute $80.4 \%$ of total spending in the data.

Non-durables are also driving most the changes in expenditures after layoff. Figure 6b displays DD results restricting attention to non-durable expenditures. The spike at layoff is smaller $(25.2 \%$ and $29.6 \%$ in months 0 and 1 , respectively) and the long-run loss is slightly smaller $(-13.1 \%$ and $-16.7 \%$ for the unconditional and survival samples, respectively) than in Figure 4 a. Therefore, non-durables respond less strongly to changes in income than the other categories included in total spending (e.g., durables) ${ }^{36}$ Yet, because non-durables account for $80.4 \%$

\footnotetext{
${ }^{34}$ We define cells using quintiles of the wage and the SP amount, and dummy variables for being older than the median age, having a high school degree, and being female. We then reweight observations such that the cells have the same weight in the treatment and control groups as in the benchmark sample.

${ }^{35}$ Durables include personal electronics, home appliances, furniture, vehicles and vehicle parts, and other durable. Non-durables excluding food include fuel (2.9\%; gas stations), personal goods (about $32.56 \%$; apparel, cosmetics, entertainment, travels, decoration), pharmacy and health-related expenditures (about $3.4 \%$; mostly pharmacy expenditures), temptation goods (less than $1 \%$; tobacco, gambling) and other non-durables (about 3\%; e.g., office supply, pet stores). Food includes groceries (about 37.4\%) and food away (about 3.2\%). Home improvement (about 4.3\%) includes expenditures related to building materials for renovations and construction. "Other" (about 1\%) are sector codes that are not specific enough to be classified and "missing" (about 4\%) are cases where the sector code is unknown. We also show that the composition of spending is similar for the control group in Appendix Figure A6a.

${ }^{36}$ Appendix Figures A6b and A6c show the results for durables and home improvement, separately.
} 
of total spending in the data, these figures imply that non-durables account for $63.1 \%-64.5 \%$ of the spike at layoff and $74.2 \%-77.2 \%$ of the long-term loss 37

The fact that durables do not drive our results is important for interpreting spending patterns as consumption responses. However, there could still be concerns around the types of goods that are purchased within non-durables. Similarly to other work in the literature (e.g., Baker and Yannelis 2017, Ganong and Noel 2019), expenditures are classified based on the merchant that issues the receipt. One limitation of this approach is that we cannot observe the durability of specific products, which could induce a difference between the timing of spending and consumption. Nonetheless, we show the robustness of our results to using sub-categories of non-durables in the remaining panels of Figure 6.

Figure 6c displays DD estimates for "strict non-durables" defined as in Lusardi (1996). That category excludes semi-durables such as apparel, education related (e.g., bookshops) and health-related (e.g., pharmacies) expenditures (see Appendix Table B1 for more details). The patterns are similar in Figures $6 \mathrm{p}$ and 6 c, but the increase at layoff is smaller for strict non-durables $(17.2 \%$ and $17 \%$ in months 0 and 1 , respectively) and so is the long-term loss $(-8.9 \%$ and $-11 \%$ for the unconditional and survival samples, respectively). This is because the main categories left in strict non-durables are food and transportation fuel (e.g., gas stations): we find similar estimates in Figure $6 \mathrm{~d}$ where we restrict attention to food expenditures only (mainly grocery shops and restaurants) ${ }^{38}$ These items are necessities and so are less likely to respond strongly to changes in income. Yet, there is a substantial response of spending to cash-on-hand for these categories.

Another approach to alleviate concerns that workers might be buying durable items within categories that we classify as "non-durables" is to look at item values, with the idea that durables are likely to be more expensive items (for which liquidity constraints are more likely to matter). Figure 6e shows that the results are similar to the results for strict non-durables when we restrict attention to items costing less than $\mathrm{R} \$ 25$ ( US $\$ 12.5$ ) within non-durable categories.

A separate concern for interpreting our results as consumption responses is the possibility of consumers substituting purchases from formal to informal stores when experiencing a negative employment shock. In this case, we might underestimate the increase at layoff and overestimate the long-run loss ${ }^{39}$ We cannot address this concern directly because we cannot measure informal expenditures. However, we can address it indirectly by considering pharmacy expenditures. Pharmacies in Brazil do not sell the same wide range of products as in the U.S.; they are more focused on health-related products as in the U.K. The household survey used in Figure 3 a reveals that $97 \%$ of the types of goods bought in a phar-

\footnotetext{
${ }^{37}$ These figures are calculated as follows: $.804 *(.252) /(.314)=64.5 \%$ and $.804 * .296 / .377=63.1 \%$ for the spike at layoff in months 0 and 1 , respectively; $.804 *(-.131) /(-.142)=74.2 \%$ and $.804 *$ $(-.167) /(-.174)=77.2 \%$ for the long-term loss in the unconditional and survival samples, respectively.

${ }^{38}$ Appendix Figures A6d and A6e show the results for groceries and food away from home, separately.

${ }^{39}$ In contrast, we might underestimate the spike at layoff and the long-run loss if workers are less likely (resp. more likely) to provide their ID to sellers at layoff (resp. in the long run) because of income effects.
} 
macy are actually bought in formal shops, such that the informality margin is mostly irrelevant. Products sold in pharmacies are also less likely to be "bingeable," so we should expect a smaller increase at layoff. Appendix Figure A6f shows a significant but much smaller increase at layoff (around 5\%). In contrast, the long-run loss is even larger than for total expenditures (around -35\%).

Finally, we show that the estimated increase in non-durable spending at layoff is similar for women and men in Appendix Figure A7. This addresses the concern that our results might be driven by changes in the share of household purchases made by workers after layoff (as we observe individuals and not families), to the extent that it is less likely to vary for women than for men in the Brazilian context.

In the rest of the paper, we focus on non-durables and interpret our results as consumption responses. Average non-durable expenditures in our data amount to $35 \%$ of average non-durable expenditures in the survey data (see Appendix Figure B2). Using this figure and comparing again the increase in expenditures to the increase in financial resources, we obtain a lower-bound for the marginal propensity to spend on non-durables of .22 over the first three months after layoff.

\section{Heterogeneity in job displacement insurance benefits}

We end this section by exploring some heterogeneity across workers in terms of the job displacement insurance benefits that they were eligible for after layoff.

SP amount. Figure 7 a compares DD estimates for workers who were eligible for different SP amounts at layoff. As we explained in Section I.B, the SP amount is a function of job tenure, so we compare workers in the top and bottom quartiles of the tenure distribution at layoff. We also restrict attention to workers with more than 24 months of tenure at layoff such that they all have the same potential UI duration, and we control flexibly for wages to net out variations in the UI replacement rate. In particular, we use the following specification:

$$
\begin{aligned}
y_{i t k}= & \sum_{q \in\{1,4\}} \sum_{k \neq k^{\prime}}\left(\alpha_{k q} \cdot 1\left\{\text { Tenure }_{i} \in Q_{q}\right\}+\beta_{k q} \cdot \text { Treat }_{i} \cdot 1\left\{\text { Tenure }_{i} \in Q_{q}\right\}\right) \\
& +\sum_{k \neq k^{\prime}}\left(\delta_{k} \cdot f\left(\text { Wage }_{i}\right)+\eta_{k} \cdot \text { Treat }_{i} \cdot f\left(\text { Wage }_{i}\right)\right)+\alpha_{i}+\alpha_{t}+\epsilon_{i t k}
\end{aligned}
$$

where the sets $Q_{q}$ correspond to the first and fourth quartiles of the tenure distribution among treatment workers with more than 24 months of tenure. The coefficients $\alpha_{k q}$ capture event-time fixed effects for each quartile (we assign control workers to the quartile corresponding to their tenure at "placebo" layoff). The coefficients $\beta_{k q}$ capture DD estimates for each quartile, separately. The coefficients $\delta_{k}$ and $\eta_{k}$ control for wage effects that are allowed to differ in the treatment and control groups ${ }^{40}$ On average, the SP replacement rate (SP amount/pre-layoff

\footnotetext{
${ }^{40}$ The function $f(\cdot)$ is a third-order polynomial in wages. We do not use weights when estimating the specification in equation 22 because we exploit variation in SP amount and control for wages directly.
} 
wage) reaches $427 \%$ and $745 \%$ in the bottom and top quartiles, respectively.

Figure 7 a displays the estimated $\widehat{\beta_{k q}}$ 's (divided by the mean in the reference month for treatment workers in the respective quartile) for non-durables using the unconditional sample. Estimates in months 0 and 1 are much larger in the top quartile $(+28.4 \%$ and $+41.4 \%$, respectively, vs. $+24.6 \%$ and $+30.5 \%$ in the bottom quartile), but they converge by month 5 such that the increase in consumption is concentrated in the first months after layoff. Moreover, Appendix Figure A8a shows that, controlling for wages, the estimated consumption levels were similar between the two groups prior to layoff 40 Thus, the differential pattern between the two groups around the time that lump-sum benefits are disbursed more clearly links the increase in consumption at layoff to these benefits.

The above estimates imply a lower bound for the marginal propensity to spend on non-durables over the first three months after layoff of .31 and .16 for the bottom and top tenure quartiles, respectively. One would expect the marginal propensity to consume (MPC) to decrease as workers receive larger SP amounts. Workers may also disproportionally increase spending on other categories following large increases in cash-on-hand, including categories not captured in our data. For instance, $22 \%$ of the UI applicants in our survey report planning to use the lump-sum amounts received at layoff to repay debts (see Appendix Table C3).

UI replacement rate. Figure $7 \mathrm{~b}$ compares DD estimates for workers who were eligible for different UI replacement rates. The only variation that we can use comes from variation in wages, which determine the UI benefit level. Specifically, we compare workers in the top and bottom quartiles of the wage distribution in the treatment group (after restricting attention again to workers who had more than 24 months of tenure at layoff). The average UI replacement rates is smaller in the top wage quartile $(38 \%)$ than in the bottom wage quartile $(83 \%)$, but the average UI benefit level is larger (the average wage is about five times larger).

Figure $7 \mathrm{~b}$ displays results for the unconditional sample from estimating a similar specification as in equation (2), but using wage quartiles instead of tenure quartiles and controlling flexibly for tenure ${ }^{42}$ The spending increase at layoff is slightly larger for workers with higher UI replacement rates. It is worth emphasizing that this pattern may not be driven by differences in UI replacement rates. As shown in Appendix Figure A8b, the estimated consumption levels were very different between the two groups prior to layoff (even controlling for tenure) given their large difference in wages. The most interesting difference appears in months 3 to 5 after layoff. While consumption continues to decrease in the top wage quartile, it remains relatively flat for workers with higher UI replacement rates. The drop in consumption when they start exhausting their UI benefits is then much steeper for these workers ${ }^{43}$ This differential pattern more clearly links the consumption

\footnotetext{
${ }^{41}$ Appendix Figures A8 also displays results for the survival sample, together with the survival rates.

${ }^{42} \mathrm{As}$ for the results in Figure $7 \mathrm{a}$, we do not use weights when estimating the specification in equation 2 because we exploit variation in wages and control for a main source of variation in SP amount directly.

${ }^{43}$ In later months, lower-wage workers fare better in relative terms, perhaps because informal work opportunities are closer substitutes to formal jobs for lower-skilled workers. Appendix Figure A8 also
} 
drop around UI exhaustion in previous figures to the UI program.

The estimates over the first three months after layoff imply a lower bound for the marginal propensity to spend on non-durables of .21 and .13 for the bottom and top wage quartiles, respectively. One would expect the MPC to be higher among lower-income workers. We estimate the marginal propensity to spend implied by the consumption drop around UI exhaustion in the next section, where we present event studies centered around UI exhaustion and restrict attention to UI takers.

\section{Expenditure profile around UI payment dates and UI exhaustion}

The evidence so far shows that workers increase consumption sharply at layoff despite experiencing a sizable long-term loss. Moreover, the DD estimates centered around the layoff event already indicated that workers do not seem to smooth consumption in anticipation of the drop in income at UI exhaustion. The UI exhaustion pattern in the previous section is fuzzy, however, because workers in our analysis sample exhaust UI benefits at different points in time between months 5 and 7 after layoff (see Figure 2b). To study changes in consumption around UI exhaustion more precisely, this section presents results for a similar DD strategy centered around UI exhaustion. We also use the detailed information on UI payment dates in our data to investigate the patterns of consumer spending around UI payments within a month. The sources of variation that we exploit in this section - a predictable drop in income at UI exhaustion and predictable disbursements of UI payments - provide further evidence on the sensitivity of displaced workers' consumption to the timing of benefit disbursement, and help shed light on the mechanisms behind our findings as discussed in Section IV.

\section{A. Empirical strategy}

The empirical strategy in this section builds on the analysis in the previous section. We select all cases in the data for which treatment workers were observed drawing 5 monthly UI payments, i.e., the maximum potential UI duration (we have UI payment data until 2012). For each of these 15,774 UI spells, we know the precise date and value of each monthly UI payment. We then fetch all the daily expenditures in the 8 months before and the 5 months after the last UI payment. Next, we use observations in the control group with (placebo) layoff months falling within the range observed in that subset of the treatment group. We then randomly assign (placebo) UI payment dates to each observation in the control group, using the actual distribution of payment dates in the data. Finally, we use the control group to net out overall trends in the data following a similar specification as in equation (1). The only difference is that the events are now UI payment or UI exhaustion events, so the index $k$ becomes the time to/from the UI payment or UI exhaustion events (the reference period will depend on the analysis). We present further details on each analysis below. In all cases, we use

displays results for the survival sample, together with the survival rates. 
the same reweighing as described in Section II.A to make the samples comparable to the overall analysis sample and we cluster standard errors by worker.

\section{B. Expenditure profile around UI payment dates within a month}

We use higher-frequency data within a month to study consumer spending profiles around UI payment events. Our window of analysis starts at the first UI payment date. We then divide the time between two payment dates - usually around 30 days - into four periods: three 7-day periods spanning the first 21 days since a UI payment date (the first period includes the payment date) and a fourth period including the remaining days until the next UI payment date. To investigate how consumer spending also evolves after UI exhaustion, we construct comparable time periods after the last UI payment. We randomly assign dates for 5 additional (hypothetical) UI payments after UI exhaustion, using the actual distribution of days between UI payment dates in the data. We then average expenditures by worker-event and time period. The index $k$ in equation (1) thus corresponds to quarter-month periods since the first UI payment in this analysis, and we use the period preceding the last UI payment as reference period $\left(k^{\prime}=16\right)$.

Figure 8 displays results for non-durable expenditures in relative terms by dividing the estimated $\widehat{\beta_{k}}$ 's by the mean in the treatment group in the reference period. It shows that non-durable expenditures follow a systematic pattern over the UI spell. Every month, expenditure levels increase by $20 \%$ in the 7 days following a UI payment and then decrease quickly in subsequent periods 44

To our knowledge, this is the first evidence of "payday effect" for UI benefits, and it is consistent with other findings in the literature, e.g., for food stamp payments in the U.S. (Hastings and Washington, 2010) or paydays in Iceland (Olafsson and Pagel, 2018). However, most goods effectively become durable at a high-enough frequency. We thus focus on food away from home to get closer to a consumption measure, pooling observations for the 4 periods within a month across the 5 payment months to increase statistical power. Appendix Figure A10 shows that spending on food away is higher by about $20 \%$ in the first period within a month (when UI is paid) compared to the rest of the month. This is consistent with the finding in Shapiro (2005) that similar expenditure patterns for food stamp beneficiaries in the U.S. capture actual consumption responses.

Figure $8 \mathrm{a}$ also suggests a lack of anticipation of the drop in income at UI exhaustion: the sharp increase in the 7 days after the last UI payment date is as large as increases following previous payment dates. Finally, in subsequent periods, consumer spending drops below 0, implying that workers spend less in these periods than they did in the period preceding the last UI payment date, even though some UI exhaustees start finding new jobs in these periods.

\footnotetext{
${ }^{44}$ Relatedly, Appendix Figure A9 shows similar patterns around paydays for formal employees, using the fact that monthly salaries must be paid before the fifth business day of each month in Brazil.
} 


\section{Expenditure profile around UI exhaustion}

Estimates for the time periods leading to and following the last UI payment in Figure $8 \mathrm{a}$ imply that we would find a sharp and persistent drop in non-durable spending if we were to aggregate the data in 30-day periods around UI exhaustion. Figure $8 \mathrm{~b}$ displays the results from such an analysis, using a window of 90 days before and 150 days after the last UI payment date. It present results for all UI exhaustees (as in Figure 8a) and restricting the treatment group to those who remain without a job until the end of the analysis window, separately. As we aggregate the data in 30-day periods centered around UI exhaustion, the index $k$ in equation (1) now corresponds to 30-day periods to/from UI exhaustion (period 0 is the 30-day period starting at, and including, the last UI payment date). We use the period preceding UI exhaustion as reference period $\left(k^{\prime}=-1\right)$.

Estimates are close to 0 in the periods leading to the last UI payment, confirming the lack of smoothing in anticipation of UI exhaustion. We find no evidence that UI exhaustees decrease their consumption even in the 30 days after their last UI payment in Figure 8b, despite the 8\%-13\% drop that they experience in subsequent periods (at this level of aggregation, we interpret again our estimates as capturing consumption responses). The drop in consumption at UI exhaustion is larger for UI exhaustees who remain without a job, at around 12\%-17\%, which is consistent with the larger long-term loss for the survival sample in Figure $6 \mathrm{~b} 45$ We show similar patterns in Appendix Figure A11 for the median.

In sum, the results confirm the lack of anticipation of the drop in income at UI exhaustion in Ganong and Noel (2019) for the U.S., but in a context where workers have substantial liquidity at layoff. We also find a high propensity to consume out of cash-on-hand when unemployed, which is consistent with Landais and Spinnewijn (n.d.), and that this effect is concentrated in the week of benefit payment, in line with Shapiro (2005). Comparing the drop in expenditures for UI exhaustees who remain without a job to the drop in their financial resources at UI exhaustion, we obtain a lower-bound for the marginal propensity to spend on non-durables of .23 over the first three months after UI exhaustion.

\section{Models of behavior and policy implications}

In this section, we shed light on mechanisms by estimating structural models of behavior that could rationalize our empirical findings. We show that our findings are at odds with the predictions of standard models of job-search and consumption with liquidity constraints and forward-looking agents in the UI literature (Card, Chetty and Weber, 2007; Chetty, 2008). Such models would not

\footnotetext{
${ }^{45}$ In Figure 8 8 , there is a slight decrease in consumption in period 0 in this sample. Yet, the equivalent of Figure $8 \mathrm{a}$ for this sample (see Appendix Figure A10a) shows that the spike for the 7-day period after the last UT payment is as high as in previous months. This indicates that the decrease in consumption in period 0 in Figure $8 \mathrm{p}$ comes from a change in spending towards the end of the 30-day period. It is thus not the case that workers who remain without a job, and experience a larger drop in consumption after UI exhaustion, better smooth their consumption through the drop in income at UI exhaustion.
} 
predict that workers increase consumption sharply following the increase in cashon-hand at layoff, and that they fail to save in anticipation of the drop in income at UI exhaustion. In contrast, we show that a model with present-biased workers generates both of these patterns. We end by using the model to simulate counterfactual job displacement insurance programs, which highlights the importance of their disbursement policies when consumption is over-sensitive to cash-on-hand.

\section{A. Empirical moments}

The empirical moments used as "targets" to be matched by the structural model are based on the subset of displaced workers eligible for five monthly UI benefits, and who took up UI in their first month of eligibility (10,025 observations). The main advantage of selecting this estimation sample is that all workers take up UI and exhaust UI in the same months (months 1 and 5, respectively), which allows us to align the months to/since the layoff and UI exhaustion events. 46

The grey lines in Figure 9 display the first set of moments: DD estimates for non-durables expenditures using the survival subset of our estimation sample. The increase in consumption at layoff is sharper than in Figure 6b, peaking in month 0 at $+46.1 \%$, but the cumulative increase over the first 3 months is comparable. The pattern around UI exhaustion is also sharper than in Figure 6 $\mathrm{b}$, with the drop in consumption taking place just after UI exhaustion as in Figure $8 \mathrm{~b}$. The second set of moments corresponds to the hazard rate of reemployment in each month since layoff, which we display in Appendix Figure A12. In our estimation sample, the hazard rate increases more sharply than in Figure 2k, peaking just after UI exhaustion (after month 5) and decreasing in subsequent months.

\section{B. Structural model}

We adapt the model in Card, Chetty and Weber (2007) and Chetty (2008) and impose a few additional assumptions to set up a structural model that we fit to these moments.

Inter-temporal consumption. The model is in discrete time, and in each month $t \in\{0,1, \ldots, T\}$, workers choose their consumption $c$ given their employment state. We assume time-separable preferences with CRRA utility: $\nu\left(c_{t}\right)=$ $\left(c^{1-\gamma}-1\right) /(1-\gamma)$. Workers start with asset level $a_{0}$; savings earn an interest rate $r$; and borrowing constraints prevent asset levels to fall below $\underline{a}$ at any time.

Employment states and job search. When employed, workers face a layoff probability $p$ at the end of each month. Reemployment probabilities for nonemployed workers depend on their job-search effort $h_{t} \in[0,1]$, which are normalized to correspond to reemployment probabilities in the next month. The utility cost of effort is assumed to take the form: $\psi\left(h_{t}\right)=\kappa \cdot h^{1+\theta} /(1+\theta)$, where $\theta$ captures the inverse of the elasticity of search effort with respect to the net gain from

${ }^{46}$ In so doing, the timing of UI takeup is also fixed (DellaVigna et al. 2017 , Ganong and Noel 2019). 
reemployment. In our estimations, we allow for two (unobserved) worker types with different search costs, $\kappa_{0}$ and $\kappa_{1}$, in proportion $s_{0}$ and $\left(1-s_{0}\right)$, respectively.

Income. All workers are initially employed earning wage $w_{e}$, and their only source of income risk in subsequent months comes from their employment states. The loss of their wage when non-employed is mitigated by a lump-sum SP amount $f$ received after layoff, and by a UI benefit $b$ received in months 1 to 5 after layoff if workers remain non-employed. Moreover, we make two assumptions to account for the fact that consumption does not drop to zero after UI exhaustion. First, we assume that workers have a constant exogenous source of income, i.e., other household members earn income $y$ in all months. The variable $c_{t}$ thus corresponds to household consumption. Second, we allow households to generate some income endogenously when workers are non-employed: they can exert some effort $l_{t}$, earning income $l_{t} \cdot w_{l}$ at a utility cost: $\phi\left(l_{t}\right)=\chi \cdot l_{t}^{1+\lambda} /(1+\lambda)$. The variable $l_{t}$ captures any income-generating activities, such as added-worker effects or unreported "gig" work; in our context, it is natural to interpret it as informal work carried out by the non-employed workers (and $w_{l}$ as an informal wage). Finally, we allow the reemployment wage $w_{r}$ to be lower than the initial wage.

Alternative purposes for the lump-sum at layoff. We assume that the relative changes in non-durable expenditures displayed by the grey lines in Figure 9 correspond to relative changes in consumption in the model. However, there may be a demand for lump-sum that is separate from any job displacement insurance purpose. For instance, the relative increase at layoff is larger for durables than for non-durables in the data. Moreover, in another small survey that we conducted with formal employees in São Paulo, $75 \%$ of respondents report that they would prefer a system granting them access to their FGTS account every 3 years irrespective of layoff history over the status quo (see Appendix Table C4) ${ }^{47}$ We thus allow the SP amount entering into the model to be a share $\omega \in[0,1]$ of its statutory amount $f$, such that part of the lump-sum may serve purposes not captured by the model. This also accounts for the possibility that firms comply imperfectly with their obligations at layoff (see Section I.C).

As we discuss below, the model requires $\widehat{\omega}<1$ for the predicted consumption profile to match the profile of non-durable expenditures in Figure 9 (otherwise the increase in consumption at layoff would be too large). Therefore, we also consider an alternative model in which workers consume two categories of goods in each month with utility: $\rho \cdot\left(c_{1 t}^{1-\gamma_{1}}-1\right) /\left(1-\gamma_{1}\right)+(1-\rho) \cdot\left(c_{2 t}^{1-\gamma_{2}}-1\right) /\left(1-\gamma_{2}\right)$. The first category $c_{1 t}$ captures non-durable expenditures, and its profile over time is the one used in the structural estimation; $c_{2 t}$ captures the rest of household consumption, which can respond differently to changes in income if $\gamma_{1} \neq \gamma_{2}$.

${ }^{47}$ Only $47 \%$ would prefer the monthly forced savings to be added to their wage over the status quo. 
Workers' problem. Thus, the workers' problem in each month $t$ is to solve:

$$
\begin{aligned}
& \max _{c_{t}, h_{t}, l_{t}} \nu\left(c_{t}\right)-\psi\left(h_{t}\right)-\phi\left(l_{t}\right)+\beta \cdot E\left[\sum_{n=1}^{T-t} \delta^{n} \cdot\left(\nu\left(c_{t+n}\right)-\psi\left(h_{t+n}\right)-\phi\left(l_{t+n}\right)\right)\right] \\
& \text { s.t. } c_{t}+a_{t+1}=(1+r) \cdot a_{t}+z_{t}+l_{t} \cdot w_{l} \\
& a_{t+1} \geq \underline{a} \\
&(1+r) \cdot a_{T}+z_{T}+l_{T} \cdot w_{l}-c_{T} \geq 0
\end{aligned}
$$

where expectations are taken over future employment states, $z_{t}$ is the exogenous income in the current state (e.g., $w_{e}+y$ in period 0 ), $h_{t}=l_{t}=0$ when employed, and $\delta$ is an exponential discount factor. The present-bias parameter $\beta$ allows for quasi-hyperbolic discounting when $\beta<1$. Workers can be naïve (they believe that they will not be present-biased in the future) or sophisticated (they know that they will have the same present bias in the future) about their bias.

\section{Estimation}

For a given vector of parameters, the model is solved by backwards induction 48 Some of these parameters are fixed in our estimations and calibrated using characteristics of the estimation sample when possible. We use a time horizon of $T=240$ months (the mean age is 32.8 years). Unless we estimate it, the monthly discount factor is set at $\delta=.995$. We use a coefficient of relative risk aversion of $\gamma=2$. Workers are assumed to start with zero assets $\left(a_{0}=0\right)$, they cannot borrow against their future income $(\underline{a}=0)$, and any savings yield a monthly interest rate of $r=.0025$. The layoff probability is set at $p=.03$ (the mean tenure at layoff is 30.4 months). We normalize household income to $w_{e}+y=1$ when workers are initially employed. We set $w_{e}=.43$ because we estimate a $43 \%$ drop in household income for displaced formal workers in São Paulo using the panel structure of the Brazilian monthly labor force surveys (from IBGE, 2010 as in Gerard and Gonzaga 2020). We set the statutory SP amount $f$ and the UI benefit level $b$ using the mean replacement rates $\left(b / w_{e}=.76, f / w_{e}=4.64\right)$. Without information on informal wages for our sample, we set $w_{l}=w_{r}$, but we impose that $l_{t} \in[0,1]$ such that informal earnings cannot exceed formal earnings. Finally, we set $w_{r} / w_{e}=.86$ because reemployed workers experience a $14 \%$ wage loss compared to before layoff on average.

The vector $\xi$ of remaining parameters is estimated using indirect inference as the vector that minimizes the distance: $(m(\xi)-\widehat{m})^{\prime} V(m(\xi)-\widehat{m})$. The vector $\widehat{m}$ includes the empirical moments described above. The vector $m(\xi)$ includes these

\footnotetext{
${ }^{48}$ By using a finite horizon model, which can be solved by backward induction, we avoid multiple equilibria that can arise in infinite-horizon models with sophisticated present-biased workers (Harris and Laibson 2002). As we rely on interpolation methods to solve the model, we also assume that the value functions and policy functions are continuous and monotonic. Simulations in Harris and Laibson (2002) suggest that this assumption is unlikely to have major implications in our case (with $\gamma=2$ and $\beta \simeq .7$ ).
} 
same moments as predicted by the model for a given vector $\xi$. Specifically, we simulate the consumption profile and hazard rates of reemployment for workers displaced after 30 months. The weighing matrix $V$ is a diagonal matrix containing the inverse of the variance of the empirical moments. The estimation algorithm then selects $\widehat{\xi}$ by randomly drawing a set of $N=100$ vectors of initial values for the free parameters, by finding the best estimator $\widehat{\xi}_{n}$ for each vector (i.e., a local minimum), and by selecting the best estimator among those 100 local minima.

These parameters are estimated jointly but the moments that likely identify each of them are illustrated in Appendix Figures A14-A17. In particular, the heterogeneity in search cost is necessary to rationalize the downward-sloping hazard rates of reemployment after UI exhaustion (through dynamic selection). The discount factor $\delta$ or the present-bias parameter $\beta$ are identified by the shape of the increase in consumption in the first few months after layoff (i.e., the spike and the negative slope afterward); while its height identifies the share of the statutory SP amount used for consumption purposes $\omega$. Finally, the inverse of the elasticity of informal work $\lambda$ and the cost of informal work $\chi$ are identified by the size of the drop in consumption at UI exhaustion and the level of consumption afterward.

\section{Estimation results and model fit}

Table 2 presents the estimated parameters for four different models. The black lines in Figure 9 display the predicted consumption moments for each of them; Appendix Figure A13 also displays the predicted income and asset levels over time. As all four models are similarly able to predict the hazard rates of reemployment after layoff, we only display these moments in Appendix Figure A12.

Benchmark model. Panel (a) in Figure 9 considers a benchmark model with forward-looking workers, in which we set $\delta=.995$ and $\beta=1$. Forward-looking workers would save most of their SP amount at layoff in our setting, such that the estimated model generates a smooth consumption profile, failing to predict both the spike at layoff (despite having $\widehat{\omega}=1$ ) and the drop at UI exhaustion.

Myopia model. In panel (b), we maintain the exponential-discounting assumption but estimate the discount factor $\delta$ from the data. The estimated model is able to fit the empirical moments closely. Workers consume a large share of their SP amount immediately, leading to the spike at layoff. The remainder is consumed over the next two months, leading to the negative slope after layoff. Consumption levels are flat afterward and drop sharply at UI exhaustion because workers have zero assets starting in month 3 after layof. However, the estimated monthly discount factor is $\widehat{\delta}=.69$, which is equivalent to a yearly discount factor of $1 \%$. Thus, an unrealistically high degree of impatience ("myopia") is necessary for an exponential-discounting model to rationalize the data.

Present-bias models. In panels (c) and (d), we assume quasi-hyperbolic discounting instead, estimating $\beta$ from the data but setting $\delta=.995$. Panel (c) considers the case of naïve present-biased workers. This model can fit the data relatively well with a present-bias parameter of $\widehat{\beta}=.44$. Yet, the fit is not as 
good as in panel (b). This suggests that a model with both naïve present bias and some degree of myopia might better fit the data. We show in Appendix Table A3 that the fit is indeed better if we estimate both $\beta$ and $\delta$ from the data. However, the present-bias parameter is $\widehat{\beta}=1$ (with $\widehat{\delta}=.69$ as in the myopia model).

Panel (d) considers the case of sophisticated present-biased workers. The fit of that model improves compared to the naïve case and approaches the fit of the myopia model for the consumption moments. The estimated present-bias parameter is also higher at $\widehat{\beta}=.70$. Both naïve and sophisticated present-biased workers want to spend following the cash inflow at layoff, but they would also like to support their consumption after UI exhaustion if possible. Naïve workers believe that their future consumption will be less sensitive to cash-on-hand, but sophisticated workers know that any savings will be consumed quickly by their future selves (before UI exhaustion). Without commitment device, the propensity to save is thus lower with sophistication in our model, which is why it can predict a similar spike at layoff with a smaller degree of present-bias (a higher $\beta$ ) 49

\section{E. Implied marginal propensities to consume (MPCs) and out-of-sample fit}

In Table 3, we further evaluate these four models by assessing how well they predict estimates of MPCs from the empirical analysis. Column (1) displays estimates of the marginal propensity to spend on non-durables based on different sources of variations in the data. Columns (2)-(5) present MPCs based on similar sources of variation in cash-on-hand, as predicted by each of the four models, respectively. To be comparable, the model-based MPCs are scaled by the share of non-durables out of total household expenditures in the POF survey data (0.401).

First, we consider the MPC over the first three months after layoff. We obtained an MPC of .22 in Section II.C using the change in cash-on-hand in the main analysis sample. In line with the results in Figure 9, the benchmark model fails to predict that moment but the myopia and present-biased models match it well. The MPC in these models is lower than its maximum value (.401) despite the fact that workers deplete their SP amount in the first three months after layoff in panels (b)-(d) in Figure 9. This is because part of the lump-sum is estimated to be used for alternative purposes not captured by the model $(\widehat{\omega}<1)$ and because the lump-sum may crowd-out households' income-generating activities $\left(l_{t}\right)$.

The following two rows in column (1) display similar estimates of the MPC at layoff, but for subsamples of workers reemployed in month 4 (see Figure 5) and not yet reemployed by month 12 (see Appendix Figure A3). These are interesting "out-of-sample" moments: because of dynamic selection, the two samples include mostly workers of the lower-cost type $\left(\kappa_{0}\right)$ and of the higher-cost type $\left(\kappa_{1}\right)$, respectively. Forward-looking workers should spend less at layoff, and thus have a lower MPC, if they expect to remain non-employed longer. This is what the

\footnotetext{
${ }^{49}$ Sophistication also affects job-search. Present-biased workers would like to exert less effort today and more effort in the future. But sophisticated workers know that they will also be biased in the future. Everything else equal, sophisticated workers thus exert more effort than naïve workers in this model.
} 
benchmark model predicts. In the data, however, the MPC is identical in the two samples, which is precisely what the myopia and present-biased models predict.

In Section II.D, we find a lower MPC at layoff (.16) for workers in the top quartile of the tenure distribution and a higher MPC (.31) for those in the bottom quartile, who have an average SP amount 58\% larger and 10\% smaller than in the main sample, respectively. This suggests that the MPC might be decreasing in the SP amount, although this heterogeneity could be affected by other characteristics correlated with tenure (even controlling for wages). The model has two mechanisms through which the MPC could change with cash-on-hand: changes in the propensities to save or to generate additional income. Table 3 shows that, with these two mechanisms only, the estimated models are unable to predict these out-of-sample moments. We come back to this point at the end the next section.

In Section II.D, we also find a higher MPC at layoff (.21) for workers in the bottom quartile of the wage distribution and a lower MPC (.13) for those in the top quartile, who have an average UI replacement rate of $83 \%$ and $38 \%$, respectively. This difference in MPCs can hardly be attributed to differences in UI replacement rates given the large differences in wages and consumption levels prior to layoff. Nevertheless, calibrating our fixed parameters using the characteristics of these two samples, Table 3 shows that the myopia and presentbiased models are able to predict this difference in MPCs relatively well.

Next, we consider the MPC estimated from the drop in income at UI exhaustion in Section III.C. The benchmark model fails to predict that moment but the other models match it better, which is also in line with the results in Figure 9. Finally, we computed the MPC over the first three months after separation for the fired sample (see Figure 4b) given their drop in cash-on-hand at separation. All four models are able to match that moment. This is also the case for the benchmark model because workers arrive with limited savings at separation 50

In sum, while the myopia model achieves the best within-sample fit, models with present-biased workers can match the target empirical moments with parameter values that are more in lines with the literature (Ericson and Laibson 2019) and perform similarly at predicting out-of-sample moments. Moreover, we show in the Appendix that this conclusion is robust to assuming a different curvature for the utility of consumption (i.e., $\log$ utility or $\gamma=1$ ) ${ }^{51}$ Present-bias is a mechanism that is also consistent with findings from our survey of UI applicants. A majority of respondents say that they would not want to receive all their UI benefits in a lump-sum fashion at layoff despite the clear financial advantage, and mention the need "to control expenditures" or "to not spend it all at once" to explain their choice (see Appendix Table C4). This also suggests some degree of sophistication. Finally, this mechanism has the advantage of providing a rationale

\footnotetext{
${ }^{50}$ We assume that workers do not take the (empirically low) risk of firing into account.

${ }^{51}$ See Appendix Figures A18-A19 and Tables A1-A2. The estimated discount factors are higher with log utility - particularly for the naïve present-bias model - because consumption-smoothing incentives are lower. Appendix Figures A20 and A21 also show that our results are robust to assuming a higher initial asset level $\left(a_{0}=2\right)$.
} 
for the existence of forced savings accounts, such as the one that exists in Brazil.

\section{F. Alternative models}

There are a number of other mechanisms that have been proposed to explain the excess sensitivity of consumption to cash-on-hand in various settings.

Models with forward-looking but liquidity-constrained agents can explain why expenditures may be very sensitive to cash-on-hand for transitory positive income shocks (Kaplan and Violante, 2014). Workers may also discover "lumpy" consumption needs over time that they cannot meet unless they have enough liquidity (Campbell and Hercowitz, 2019). This could explain the response of durable expenditures at layoff, but our main results are not driven by durables. More importantly, this class of models cannot explain why agents would fail to save in anticipation of an expected drop in income, such as the one workers experience at UI exhaustion. This point, which was made by Ganong and Noel (2019) for the U.S., is even more striking in the context that we study. Displaced workers tend to have limited financial resources at layoff in the U.S. In contrast, Figure 9a indicates that workers in our sample could smooth consumption well beyond UI exhaustion if they dissaved their cash-on-hand at layoff more slowly 52

Models in which displaced workers are forward-looking but have biased and optimistic beliefs about their future reemployment probabilities (or income path) could predict a lack of savings in anticipation of UI exhaustion (Spinnewijn, 2015). However, these workers would not have a high propensity to consume out of cashon-hand at layoff because of the diminishing marginal utility of consumption. For instance, we show in Appendix Figure A24 that even introducing widely optimistic beliefs into the benchmark model is not sufficient to generate a large increase in consumption at layoff, and workers would perfectly smooth consumption at UI exhaustion. Arguably, a naïve present-bias model embeds optimistic beliefs about reemployment probabilities as workers believe that they will exert more search effort in the future. However, biased beliefs alone cannot explain the data. 53

Ganong and Noel (2019) propose a model with naïve present-biased workers to explain the drop in consumption at UI exhaustion in the U.S. Their model would also predict some excess sensitivity to cash-on-hand at layoff if workers were to receive a transitory positive income shock as in our context. However,

\footnotetext{
${ }^{52}$ In Gerard and Naritomi (2019), we show that a model with forward-looking workers facing severe saving constraints could be consistent with our findings. However, it is unlikely that workers in our sample face severe savings constraints. Most of them likely have bank accounts (e.g, the share is $93 \%$ in our survey of UI applicants; see Appendix C). Expenditure pressures from individuals' kin network could generate savings constraints. However, only $2 \%$ of UI applicants in our survey mention transfers to friends and family as an important category of spending for their lump-sum amount (see Appendix C). Arguably, expenditure pressures from one's kin network may be weaker after a salient negative shock.

${ }^{53}$ Complementarities between consumption and leisure are also unlikely to rationalize our findings. Models in which consumption spendings are substitutes with leisure (Aguiar and Hurst, 2005) would explain neither the spike in consumption at layoff (displaced workers likely have more time in hand) nor the drop in consumption after UI exhaustion (workers do not have more time in hand). Models in which consumption is a complement to leisure would not explain why the spike at layoff is similar for workers reemployed immediately in Figure 5 (they do not have more time in hand after layoff).
} 
their model requires a large degree of heterogeneity in present bias across workers, while our model does not. This is because our model allows households to partially self-insure by generating extra income while workers remain non-employed. Allowing for this additional mechanism of consumption-smoothing (besides savings) is relevant for countries with high informality, but it is likely relevant for richer countries as well (e.g., added-worker effects). We show in the Appendix that heterogeneity in present bias is unlikely to play a major role in our case. We re-estimated the naïve present-bias model allowing for two present-bias types. As in Ganong and Noel (2019), the estimated model fits the data well with a present-biased type $\left(\widehat{\beta_{0}}=.30\right)$ and a more patient type $\left(\widehat{\beta_{1}}=.96\right.$; see Appendix Table A3 and Figures A22-A23). Yet, it performs worse than the models without heterogeneity in present bias at predicting the out-of-sample moments in Table 3. Specifically, dynamic selection in this model implies that workers reemployed in month 4 after layoff are mostly of the more patient type, while workers not yet reemployed by month 12 are mostly of the present-biased type. As a result, the predicted MPC at layoff is very different between the two samples, i.e., much lower in the first sample (see Appendix Figure A25 and Table A4). This is not the case in our data.

Finally, we present results for the model with two consumption categories (see Section IV.B in the Appendix, which is a relevant extension given that we estimate $\widehat{\omega}<1$ in columns (2)-(4) in Table 2. For the estimation, we set $\omega=1$ and $\gamma_{1}=2$; we let $\gamma_{2}=\alpha \cdot \gamma_{1}$ to be a free parameter, i.e., we estimate $\alpha$; and we set $\rho$ such that non-durables account for .401 of total consumption before layoff (as in the POF data). The estimated models with naïve and sophisticated presentbiased workers fit the empirical moments well with similar degrees of present-bias, $\widehat{\beta}=.44$ and $\widehat{\beta}=.73$, respectively (see Appendix Table A3 and Figures A22-A23). The curvature of the utility over $c_{2 t}$ is also smaller, with $\widehat{\alpha}=0.37$. As a result, the share of non-durables in total consumption is decreasing in cash-on-hand and the model is now able to generate a marginal propensity to spend on non-durables that is lower for workers receiving a larger SP amount (see Appendix Table A4) 54

\section{G. Counterfactual job displacement insurance designs}

Our results have relevant implications for job displacement insurance programs, which we illustrate in Figure 10. It displays the predicted consumption profile and hazard rates of reemployment for counterfactual policies using our preferred estimated model, the sophisticated present-bias model (see Appendix Figure A26 for the case of naïve present-biased workers). We first assume no job displacement insurance benefits. Then, we consider (i) a UI program paying the same average

\footnotetext{
${ }^{54}$ Explicitly modeling $c_{2 t}$ as a durable good would likely lead to the same prediction Browning and Crossley, 2009). The one out-of-sample moment that even this model cannot match is the MPC at layoff for the bottom quartile of the tenure distribution. This is because the marginal propensity to spend on non-durables is much higher in this sample, even though the average SP amount is only $10 \%$ smaller. This could be consistent with sizable adjustment costs or indivisibilities in durable investments.
} 
benefit level as in the estimation sample for a potential UI duration of 5 months after layoff; (ii) a SP program paid in a lump-sum fashion at layoff; and (iii) a SP program paying the same amount in 5 monthly installments irrespective of workers' reemployment status. This third (untested) program allows us to highlight the role of disbursement policies. The three programs are designed such that their mechanical cost - their cost assuming the same search efforts as with no benefits - is the same, and a per-period tax is levied prior to layoff to pay for that cost. Moreover, the full SP amount is used for consumption purposes in this exercise, i.e., we assume that the only goal of these programs is to insure against the risk of layoff. Thus, the insurance embodied in such programs is that workers who are laid off late transfer resources towards those who are laid off early ${ }^{55}$

Figure 10 also displays the expected welfare effect of each of these programs, compared to the no-benefits case, based on simulating 1500 employment histories. For the sake of comparability with the UI literature, we present three welfare components separately 56 The insurance value captures the standard welfare effect from their consumption-smoothing gains. It is obtained by solving the model for each program keeping search efforts fixed at their no-benefits levels. The incentive effect is the standard measure of efficiency loss from behavioral responses to such programs in the UI literature. It is measured by their fiscal externality, i.e., the ratio of the increase in programs' cost once workers adjust search efforts (the behavioral effect) to their cost absent behavioral responses (the mechanical effect; see, e.g., Gerard and Gonzaga 2020). Finally, the third component captures any additional change in workers' welfare from adjusting search efforts. All values are expressed in $\$ 1$ per $\$ 1$ spent on targeted beneficiaries (Chetty, 2008). In all our calculations, we assume that normative preferences are free of present bias.

Figure 10 a shows that consumption drops sharply at layoff with no benefits. With the three policies, consumption levels are slightly lower prior to layoff (because of the tax) and then diverge after layoff. Given the relatively high replacement rate, the UI program leads workers to perfectly smooth consumption in the first five months after layoff. The SP paid in installments also allows workers to smooth consumption in these months. However, consumption levels are lower than with the UI program. The monthly installments are paid unconditionally, so they cannot be as high as the monthly UI benefits holding total costs fixed. This is a typical advantage of UI: by being contingent on workers remaining nonemployed, UI benefits can provide better insurance than SP programs against the risk of remaining non-employed. Finally, paying the same SP amount in a lumpsum fashion at layoff leads to a large increase in consumption at layoff, but the same low levels of consumption as with no benefits by month 2 after layoff already. The difference between these two SP programs thus highlights the relevance of disbursement policies for the consumption-smoothing gains of job displacement

\footnotetext{
${ }^{55}$ Assuming that their cost falls on workers, it is irrelevant whether the programs are explicitly managed by the government (funded through a tax) or implicitly by the firms (funded through a wage cut).

${ }^{56}$ For the same reason, we also assume that new jobs are never lost once workers are reemployed after layoff in these counterfactual simulations (Chetty, 2008).
} 
insurance designs when consumption is over-sensitive to cash-on-hand.

Figure 10p shows that UI and SP programs also have different implications regarding job-search efforts. The UI program disincentivizes reemployment, generating a reemployment pattern similar to the one in our data. In contrast, the SP programs lead to smaller distortions in job-search efforts because they only affect job-search through a liquidity effect (Chetty, 2008). The two SP programs have slightly different implications regarding job-search efforts, however. In the estimated model, the liquidity effect only leads to a small decrease in the hazard rate between months 0 and 1 for the SP paid lump-sum at layoff because workers use their cash-on-hand quickly in that case. Thus, disbursement policies can also affect the impact of job displacement insurance designs on job-search efforts.

In terms of welfare effects, the patterns in Figures $10 \mathrm{a}$ and $10 \mathrm{~b}$ highlight the usual incentive-insurance trade-off in the UI literature. UI programs provide better insurance and have thus a higher insurance value than SP programs, but imply larger distortions in job-search incentives and thus a larger incentive effect. In fact, SP programs do not generate any incentive effect because changes in search efforts do not affect their budgetary cost. Paying the SP amount in installments thus increases their insurance value without changing their incentive effect.

However, Figure 10 also highlight that changes in search efforts could lead to additional welfare losses when workers are present-biased, which would be unaccounted for using the usual sufficient statistics formulas in the UI literature. A usual revealed-preference argument implies that any adjustment in search effort necessarily increases workers' own welfare if workers are forward-looking. However, present-biased workers exert sub-optimally low search efforts from their own perspective, even in the no-benefits case. As a result, policies that further reduce search efforts exacerbate this "internality" (Lockwood, n.d.), potentially lowering workers' own welfare. Taking into account job-search internalities is particularly important in the case of UI programs, given that they lead to larger distortions in job-search incentives. Yet, the changes in search efforts with SP programs also exacerbate job-search internalities, and the larger reduction in search efforts when the SP amount is paid in installments imply larger impacts on these internalities.

\section{Conclusion}

This paper documents evidence that consumption is highly sensitive to cash-onhand, even in a context where a large transitory inflow of liquidity is triggered by a salient and persistent negative shock. We use the evidence on consumer spending responses to various sources of variation in benefits to discuss mechanisms, and we show that a simple model with present-biased workers is able to rationalize the key consumption and reemployment patterns in our data.

Taken together, our results imply that the disbursement policy of job displacement insurance schemes may affect their insurance value to workers. In particular, the tranched payments of UI benefits may be particularly important in helping

displaced workers better smooth consumption compared to a SP program. The 
importance of this difference in disbursement policy has been largely overlooked in the debate between UI and SP, which focuses on their different contingency policy (i.e., UI benefits are contingent on workers remaining non-employed) and its implications for moral hazard and targeting. Our results also suggest that disbursement policies could play an important role in other policy contexts. For instance, the private retirement savings literature (e.g., the 401k literature) has emphasized how present bias may affect savings decision (e.g., Laibson et al. 1998), but it may affect dissaving decisions as well, given that workers can currently access their $401 \mathrm{k}$ balances in a lump-sum fashion at retirement in the U.S.

It is worth emphasizing that our results do not imply that lump-sum disbursements should generally be avoided. The same behavioral failure that prevents workers from dissaving their SP amount more slowly may justify the existence of forced savings to mobilize the resources necessary for lumpy investments that workers may not be able to make otherwise (e.g., Casaburi and Macchiavello 2019). However, if the goal of a policy is to provide insurance to displaced workers, our results imply that a lump-sum disbursement could undermine this goal. Workers may still benefit from forced savings and occasional access to these financial resources in a lump-sum fashion for other purposes or at other times.

In terms of the design of job displacement insurance programs, the simulations in Section IV.G help illustrate the implications of our empirical findings, but we are careful to not draw definitive normative conclusions. First, several papers in the UI literature argue for using much higher values for the coefficient of relative risk aversion (e.g., Landais and Spinnewijn, n.d.), which would widen the differences in consumption-smoothing gains between alternative programs. Second, internalities and their interactions with policy reforms could be more complex in richer models with additional choice variables or sources of bias.

Finally, our findings shed light on directions for future research. In particular, it would be important to build evidence on the impact of alternative policies beyond UI and SP. For instance, in the Unemployment Insurance Savings Account (UISA) system discussed in Feldstein and Altman (2007), workers' UI benefits essentially come from pensionable forced savings accounts. The supposed benefit of such a system is that it would lead to smaller distortions in job-search efforts compared to a regular UI system because workers would internalize the gains of having additional wealth in retirement if they draw fewer UI benefits during their work life. This argument becomes much weaker, however, if workers are presentbiased (Chetty and Finkelstein, 2013). Present bias could motivate a system of forced savings accounts for job displacement insurance purposes, but the optimal way to give workers access to such accounts considering implications for both consumption-smoothing and job search remains an open question.

\section{REFERENCES}

Aguiar, M., and E. Hurst. 2005. "Consumption versus Expenditure." Journal of Political Economy, 113(5): 919-948. 
Anonymous firm. 2017. "Receipts data 2010-2016." Access granted on 201701-06.

Baily, Martin. 1978. "Some Aspects of Optimal Unemployment Insurance." Journal of Public Economics, 10: 379-402.

Baker, Scott R. 2018. "Debt and the response to household income shocks: Validation and application of linked financial account data." Journal of Political Economy, 126(4): 1504-1557.

Baker, Scott R, and Constantine Yannelis. 2017. "Income changes and consumption: Evidence from the 2013 federal government shutdown." Review of Economic Dynamics, 23: 99-124.

Browning, Martin, and Thomas Crossley. 2009. "Shocks, Stocks, and Socks: Smoothing Consumption Over a Temporary Income Loss." Journal of the European Economic Association, 7(6): 1169-1192.

Campbell, Jeffrey, and Zvi Hercowitz. 2019. "Liquidity Constraints of the Middle Class." American Economic Journal: Economic Policy, 11(3): 130-155.

Card, David, Raj Chetty, and Andrea Weber. 2007. "Cash-on-Hand and Competing Models of Intertemporal Behavior: New Evidence from the Labor Market." Quarterly Journal of Economics, 122(4): 1511-1560.

Casaburi, Lorenzo, and Rocco Macchiavello. 2019. "Demand and supply of infrequent payments as a commitment device: evidence from Kenya." American Economic Review, 109(2): 523-55.

Chetty, Raj. 2006. "A General Formula for the Optimal Level of Social Insurance." Journal of Public Economics, 90: 1879-1901.

Chetty, Raj. 2008. "Moral Hazard versus Liquidity and Optimal Unemployment Insurance." Journal of Political Economy, 116(2): 173-234.

Chetty, Raj, and Amy Finkelstein. 2013. "Social Insurance: Connecting Theory to Data." Handbook of Public Economics, 5: 111-193.

DellaVigna, Stefano, Attila Lindner, Balazs Reizer, and Johannes Schmieder. 2017. "Reference-Dependent Job Search: Evidence from Hungary." Quarterly Journal of Economics, 132(4): 1969-2018.

Ericson, Keith Marzilli, and David Laibson. 2019. "Intertemporal Choice." Handbook of Behavioral Economics - Foundations and Applications, 2.

Feldstein, Martin, and Daniel Altman. 2007. "Unemployment insurance savings accounts." Tax policy and the economy, 21: 35-63. 
Ganong, Peter, and Pascal Noel. 2019. "Consumer Spending during Unemployment: Positive and Normative Implications." American Economic Review, 109(7): 2383-2424.

Gathergood, John, Neale Mahoney, Neil Stewart, and Jörg Weber. 2019. "How Do Individuals Repay Their Debt? The Balance-Matching Heuristic." American Economic Review, 109(3): 844-75.

Gelman, Michael, Shachar Kariv, Matthew D Shapiro, Dan Silverman, and Steven Tadelis. 2014. "Harnessing naturally occurring data to measure the response of spending to income." Science, 345(6193): 212-215.

Gerard, François, and Gustavo Gonzaga. 2020. "Informal Labor and the Efficiency Cost of Social Programs: Evidence from Unemployment Insurance in Brazil." American Economic Journal: Economic Policy, Forthcoming.

Gerard, François, and Joana Naritomi. 2017. "Cross-country dataset on job displacement insurance programs." Accessed on 2018-01-01.

Gerard, François, and Joana Naritomi. 2018. "Survey with UI applicants and formal employees in São Paulo." Accessed on 2018-08-31.

Gerard, François, and Joana Naritomi. 2019. "Job displacement insurance and (the lack of) consumption-smoothing." NBER Working Paper No. 25749.

Harris, Christopher J., and David Laibson. 2002. "Hyperbolic Discounting and Consumption." In Advances in Economics and Econometrics: Theory and Applications, Volume 1., ed. Mathias Dewatripont, Lars Peter Hansen and StephenTurnovsky, 258-298. Eighth World Congress.

Hastings, Justine, and Ebonya Washington. 2010. "The First of the Month Effect: Consumer Behavior and Store Responses." American Economic Journal: Economic Policy, 2(2): 142-162.

Hastings, Justine, and Jesse M Shapiro. 2018. "How are SNAP benefits spent? Evidence from a retail panel." American Economic Review, 108(12): 3493-3540.

Hendren, Nathaniel. 2017. "Knowledge of Future Job Loss and Implications for Unemployment Insurance." American Economic Review, 107 (7): 1778-1823.

Holzmann, Robert, Yann Pouget, Milan Vodopivec, and Michael Weber. 2012. "Severance Pay Programs around the World: History, Rationale, Status, and Reforms." Reforming Severance Pay: An International Perspective, Chapter 2, 17-120. Washington DC:The International Bank for Reconstruction and Development, The World Bank. 
Instituto Brasileiro de Geografia e Estatística (IBGE). 2010. "Pesquisa Mensal de Emprego (PME) 2003-2009." https://www.ibge.gov.br/estatisticas/sociais/trabalho/9180-pesquisa-mensalde-emprego.html. Accessed on 2011-07-15.

Instituto Brasileiro de Geografia e Estatística (IBGE). 2011. "Pesquisa de Orçamentos Familiares (POF) 2008-2009." Data Zoom - Pontifícia Universidade Católica do Rio de Janeiro (PUC-Rio). http://www.econ.pucrio.br/datazoom/pofMicro.html. Accessed on 2016-12-22.

Instituto Brasileiro de Geografia e Estatística (IBGE). 2016. "Índice Nacional de Preços ao Consumidor Amplo (IPCA) 2010-2014." https://www.ibge.gov.br/estatisticas/economicas/precos-e-custos/9256-indicenacional-de-precos-ao-consumidor-amplo.html? $=\mathrm{t}=$ downloads. Accessed on 2016-07-01.

Kaplan, Greg, and Giovanni L Violante. 2014. "A model of the consumption response to fiscal stimulus payments." Econometrica, 82(4): 1199-1239.

Kolsrud, Jonas, Camille Landais, Peter Nilsson, and Johannes Spinnewijn. 2018. "The Optimal Timing of Unemployment Benefits: Theory and Evidence from Sweden." American Economic Review, 108(4-5): 985-1033.

Kuchler, Theresa, and Michaela Pagel. n.d.. "Sticking to Your Plan: The Role of Present Bias for Credit Card Paydown." Journal of Financial Economics, forthcoming.

Kueng, Lorenz. 2018. "Excess sensitivity of high-income consumers." The Quarterly Journal of Economics, 133(4): 1693-1751.

Laibson, David I, Andrea Repetto, Jeremy Tobacman, Robert E Hall, William G Gale, and George A Akerlof. 1998. "Self-control and saving for retirement." Brookings papers on economic activity, 1998(1): 91-196.

Landais, Camille, and Johannes Spinnewijn. n.d.. "The value of unemployment insurance." Review of Economic Studies, forthcoming.

Lockwood, Benjamin B. n.d.. "Optimal income taxation with present bias." American Economic Journal: Economic Policy, forthcoming.

Lusardi, Annamaria. 1996. "Permanent income, current income, and consumption: Evidence from two panel data sets." Journal of Business 86 Economic Statistics, 14(1): 81-90.

Ministério do Trabalho (MTE). 2012. "Dados de Seguro Desemprego 20092012." Access granted on 2012-07-26.

Ministério do Trabalho (MTE). 2015. "Relatório Anual de Informações Sociais (RAIS) 2005-2014." Access granted on 2015-09-21. 
Naritomi, Joana. 2019. "Consumers as Tax Auditors." American Economic Review, 109(9): 3031-72.

Olafsson, Arna, and Michaela Pagel. 2018. "The liquid hand-to-mouth: Evidence from personal finance management software." The Review of Financial Studies, 31(11): 4398-4446.

Parker, Jonathan A, Nicholas S Souleles, David S Johnson, and Robert McClelland. 2013. "Consumer spending and the economic stimulus payments of 2008." American Economic Review, 103(6): 2530-2553.

Parsons, Donald. 2016. "Job Displacement Insurance: A Policy Typology." IZA Working Paper, 9865.

Pistaferri, Luigi. 2015. "Household consumption: Research questions, measurement issues, and data collection strategies." Journal of Economic and Social Measurement, 40(1-4): 123-149.

Ponce, Alejandro, Enrique Seira, and Guillermo Zamarripa. 2017. "Borrowing on the wrong credit card? Evidence from Mexico." American Economic Review, 107(4): 1335-61.

Shapiro, Jesse. 2005. "Is there a Daily Discount Rate? Evidence from the Food Stamp Nutrition Cycle." Journal of Public Economics, 89 (2-3): 303-325.

Spinnewijn, Johannes. 2015. "Unemployed but optimistic: Optimal insurance design with biased beliefs." Journal of the European Economic Association, 13(1): 130-167.

Stephens, Melvin. 2001. "The long-run consumption effects of earnings shocks." Review of Economics and Statistics, 83 (1): 28-36. 
Table 1: Descriptive statistics and representativity of the analysis sample

\begin{tabular}{|c|c|c|c|c|c|}
\hline & $\begin{array}{c}\text { Analysis } \\
\text { sample } \\
\text { (Treatment) }\end{array}$ & $\begin{array}{l}\text { Benchmark } \\
\text { sample }\end{array}$ & $\begin{array}{l}\text { Difference } \\
\quad(1)-(2)\end{array}$ & $\begin{array}{c}\text { Analysis } \\
\text { sample } \\
\text { (Control) }\end{array}$ & $\begin{array}{l}\text { Difference } \\
\quad(1)-(4)\end{array}$ \\
\hline (mean at/before layoff) & $(1)$ & $(2)$ & (3) & $(4)$ & $(5)$ \\
\hline Share working in urban area & 0.974 & 0.971 & $0.003(0.000)$ & 0.975 & $-0.000(0.000)$ \\
\hline Share working in metropolitan area of São Paulo & 0.556 & 0.535 & $0.021(0.002)$ & 0.571 & $-0.015(0.002)$ \\
\hline Share female & 0.436 & 0.391 & $0.045(0.002)$ & 0.394 & $0.042(0.002)$ \\
\hline Share with high school degree & 0.728 & 0.653 & $0.075(0.002)$ & 0.758 & $-0.030(0.002)$ \\
\hline Share white & 0.704 & 0.693 & $0.010(0.002)$ & 0.704 & $-0.001(0.002)$ \\
\hline Tenure (months) & 30.20 & 29.24 & $0.963(0.064)$ & 32.84 & $-2.64(0.066)$ \\
\hline Age (years) & 32.82 & 32.55 & $0.275(0.037)$ & 34.13 & $-1.31(0.033)$ \\
\hline Monthly wage (R\$2010) & 1,341 & 1,280 & $60.37(5.037)$ & 1,568 & $-227.4(5.12)$ \\
\hline Statutory UI benefit level (R $\$ 2010)$ & 809.5 & 786.5 & $23.1(0.765)$ & 859.1 & $-49.59(0.69)$ \\
\hline Statutory SP amount $(\mathrm{R} \$ 2010)$ & 3,093 & 2,909 & $184.0(13.11)$ & 3,874 & $-780.7(15.03)$ \\
\hline Statutory FGTS balance (R $\$ 2010)$ & 3,229 & 3,029 & $200.1(14.92)$ & 4,305 & $-1077(18.6)$ \\
\hline UI replacement rate (UI benefit/wage) & 0.751 & 0.766 & $-0.02(0.001)$ & 0.697 & $0.054(0.001)$ \\
\hline SP replacement rate (SP amount/wage) & 2.272 & 2.229 & $0.043(0.003)$ & 2.370 & $-0.09(0.002)$ \\
\hline FGTS replacement rate (FGTS balance/wage) & 2.455 & 2.399 & $0.056(0.006)$ & 2.629 & $-0.17(0.005)$ \\
\hline Monthly expenditure $(\mathrm{R} \$ 2010)$ & 459.8 & n.a. & n.a. n.a. & 538.1 & $-78.25(2.7)$ \\
\hline Number of observations & 77,892 & 156,110 & 234,002 & 220,100 & 297,992 \\
\hline
\end{tabular}

Notes: The table displays the mean of the variables in the left-hand-side column at or before layoff for displaced formal workers in the analysis sample (column 1), which is the treatment group in our empirical analysis in Section II. We assess the representativity of this sample by comparing it to a benchmark sample drawn randomly from the universe of displaced formal workers in São Paulo (column 2). We also compare it to the "placebo" displaced workers from the analysis sample (column 4), which we use as control group in Section II. Monthly expenditures are averaged over the 12 months before layoff; all monetary values in the paper are in $\mathrm{R} \$ 2010$ (US\$1 $\simeq \mathrm{R} \$ 2$ in 2010) using the IPCA index (IBGE, 2016). Columns (3) and (5) display the estimated coefficient from regressing these variables on an indicator for the treatment sample (standard errors in parentheses). 
Table 2: Estimated parameters for the structural models

\begin{tabular}{|c|c|c|c|c|c|c|c|c|}
\hline & \multicolumn{2}{|c|}{$\begin{array}{c}\delta \text {-discounting } \\
\text { with fixed } \delta \\
\text { (benchmark) }\end{array}$} & \multicolumn{2}{|c|}{$\begin{array}{c}\delta \text {-discounting } \\
\text { with free } \delta \\
\text { (myopia) }\end{array}$} & \multicolumn{2}{|c|}{$\begin{array}{c}\beta \delta \text {-discounting } \\
\text { with free } \beta \\
\text { (naïve) }\end{array}$} & \multicolumn{2}{|c|}{$\begin{array}{c}\beta \delta \text {-discounting } \\
\text { with free } \beta \\
\text { (sophisticated) }\end{array}$} \\
\hline & & [1] & & [2] & & {$[3]$} & & [4] \\
\hline \multicolumn{9}{|l|}{ Parameters } \\
\hline Discount factor (1 month): $\delta$ & 0.995 & (fixed) & 0.690 & $(0.005)$ & 0.995 & (fixed) & 0.995 & (fixed) \\
\hline Present bias parameter: $\beta$ & 1.000 & (fixed) & 1.000 & (fixed) & 0.444 & $(0.004)$ & 0.703 & $(0.004)$ \\
\hline Inverse of search elasticity: $\theta$ & 0.101 & $(0.030)$ & 0.624 & $(0.012)$ & 0.768 & $(0.014)$ & 0.171 & $(0.002)$ \\
\hline Search cost (lower-cost type): $\kappa 0$ & 5.218 & $(1.386)$ & 0.650 & $(0.022)$ & 0.601 & $(0.019)$ & 1.696 & $(0.053)$ \\
\hline Search cost (higher-cost type): $\kappa 1$ & 14.136 & $(1.557)$ & 2.158 & $(0.129)$ & 13.034 & $(0.935)$ & 10.384 & $(0.560)$ \\
\hline Share of lower-cost type: so & 0.511 & $(0.014)$ & 0.526 & $(0.013)$ & 0.468 & $(0.015)$ & 0.615 & $(0.018)$ \\
\hline Share of lump-sum amount for consumption: $\omega$ & 1.000 & $(0.164)$ & 0.661 & $(0.006)$ & 0.502 & $(0.006)$ & 0.615 & $(0.008)$ \\
\hline Informal work cost: $\chi$ & 20.234 & $(53.706)$ & 1.570 & $(0.019)$ & 5.519 & $(0.309)$ & 2.168 & $(0.073)$ \\
\hline Inverse of informal work elasticity: $\lambda$ & 1.490 & $(1.431)$ & 0.086 & $(0.006)$ & 0.927 & $(0.029)$ & 0.288 & $(0.020)$ \\
\hline \multicolumn{9}{|l|}{ Model fit } \\
\hline Number of moments used & & 30 & & 30 & & 30 & & 30 \\
\hline Number of estimated parameters & & 7 & & 8 & & 8 & & 8 \\
\hline Goodness of fit: consumption moments & & 762.23 & & 17.63 & & 86.25 & & 24.59 \\
\hline Goodness of fit: search moments & & 41.21 & & 14.97 & & 39.02 & & 53.93 \\
\hline
\end{tabular}

Notes: The table displays parameter estimates for the four versions of the structural model described in Section IV.D The parameters are estimated by minimizing the distance between the target empirical moments and the same moments as predicted by the models for a given vector of free parameters.

Table 3: Comparison of the Marginal Propensity to Consume (MPC) nondurables out of cash-on-hand in the data and in the estimated models

\begin{tabular}{|c|c|c|c|c|c|c|}
\hline \multirow{3}{*}{$\begin{array}{l}\text { Sources of variation } \\
\text { in cash-on-hand }\end{array}$} & \multirow{2}{*}{\multicolumn{2}{|c|}{$\begin{array}{l}\text { MPC from the data } \\
\qquad[95 \% \mathrm{CI}]\end{array}$}} & \multicolumn{4}{|c|}{ MPC from models } \\
\hline & & & $\begin{array}{c}\delta \text {-discounting } \\
\text { with fixed } \delta \\
\text { (benchmark) }\end{array}$ & $\begin{array}{c}\delta \text {-discounting } \\
\text { with free } \delta \\
\text { (myopia) }\end{array}$ & $\begin{array}{c}\beta \delta \text {-discounting } \\
\text { with free } \beta \\
\text { (naïve) }\end{array}$ & $\begin{array}{c}\beta \delta \text {-discounting } \\
\text { with free } \beta \\
\text { (sophisticated) }\end{array}$ \\
\hline & & [1] & {$[2]$} & {$[3]$} & {$[4]$} & [5] \\
\hline \multicolumn{7}{|l|}{ Layoff event } \\
\hline Main analysis sample & 0.224 & {$[0.210 ; 0.237]$} & -0.004 & 0.202 & 0.201 & 0.197 \\
\hline Sample reemployed in month 4 & 0.215 & {$[0.153 ; 0.278]$} & 0.016 & 0.202 & 0.201 & 0.197 \\
\hline Sample not reemployed by month 12 & 0.215 & {$[0.195 ; 0.236]$} & -0.037 & 0.202 & 0.201 & 0.197 \\
\hline Higher severance pay (SP +58\%) & 0.162 & {$[0.144 ; 0.180]$} & 0.012 & 0.216 & 0.188 & 0.190 \\
\hline Lower severance pay (SP -10\%) & 0.31 & {$[0.255 ; 0.365]$} & -0.008 & 0.193 & 0.207 & 0.195 \\
\hline Higher UI replacement rate (lower wage) & 0.214 & {$[0.172 ; 0.256]$} & 0.035 & 0.250 & 0.234 & 0.245 \\
\hline Lower UI replacement rate (higher wage) & 0.128 & {$[0.110 ; 0.147]$} & -0.062 & 0.147 & 0.096 & 0.104 \\
\hline UI exhaustion event & 0.228 & {$[0.182 ; 0.275]$} & 0.044 & 0.099 & 0.274 & 0.182 \\
\hline Firing event & 0.175 & {$[0.091 ; 0.259]$} & 0.187 & 0.146 & 0.172 & 0.162 \\
\hline
\end{tabular}

Notes: The table compares estimates of MPCs from the empirical analysis to similar MPCs as predicted by the estimated models in Table 2. Column (1) displays estimates of the marginal propensity to spend on non-durables (with their $95 \%$ confidence interval) based on different sources of variations in the data. Columns (2)-(5) present MPCs based on similar sources of variation in cash-on-hand, as predicted by each of the four models, respectively. For the sake of comparability, the model-based MPCs are scaled by the share of non-durables out of total household expenditures in the POF survey data (0.401). 
Figure 1. : Government-mandated job displacement insurance around the world (a) Western Europe, USA, CAN, AUS, NZ (25 countries)

(b) Africa, Asia, Rest of Americas (114 countries)
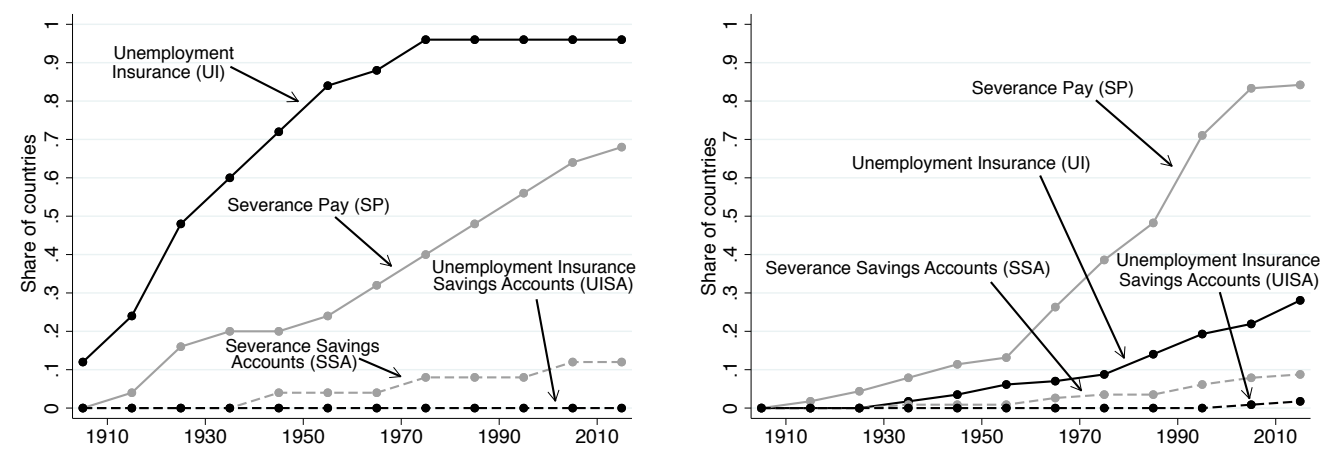

Notes: The figure displays the share of countries with government-mandated job displacement insurance programs by decade. We collected data for 139 countries (see Appendix D for details) in Western Europe, USA, Canada, Australia, New Zealand (panel a), and Africa, Asia, rest of the Americas (panel b) Gerard and Naritomi 2017). The programs are categorized based on their benefit payout schemes - lump-sum vs. state-contingent - and financing schemes - insurance-based vs. savings-based (Parsons 2016, see footnote 1), such that we display separate graphs for Unemployment Insurance (UI; state-contingent, insurance), Severance Pay (SP; lump-sum, insurance), Unemployment Insurance Savings Account (UISA; state-contingent, forced savings), Severance Savings Account (SSA; lump-sum, forced savings). 
Figure 2. : Background information and representativity of the analysis sample

(a) Average statutory benefits

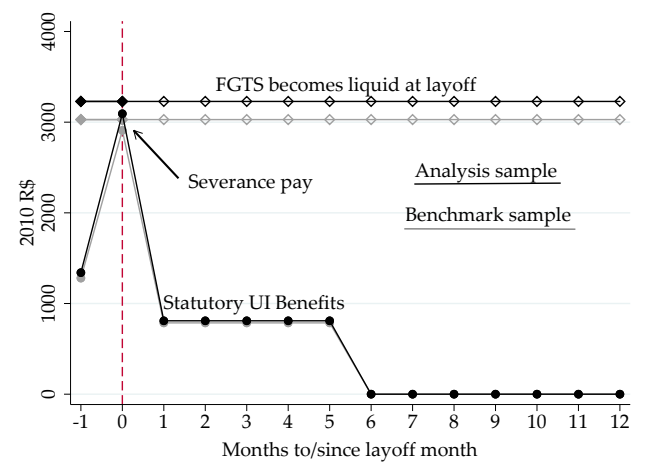

(c) Hazard rate of formal reemployment

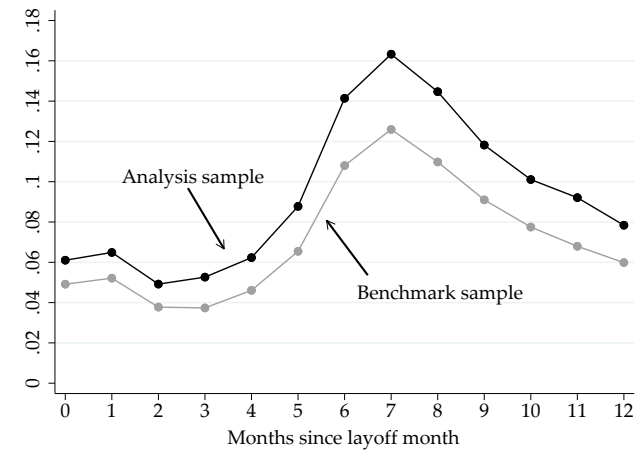

(b) Share drawing UI benefits (2011)

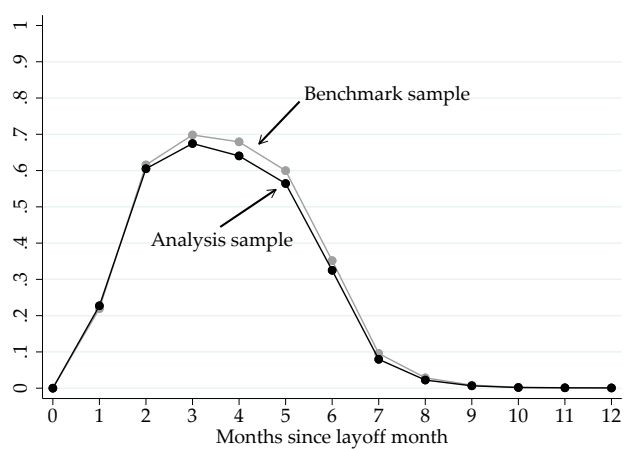

(d) Survival rate without a formal job

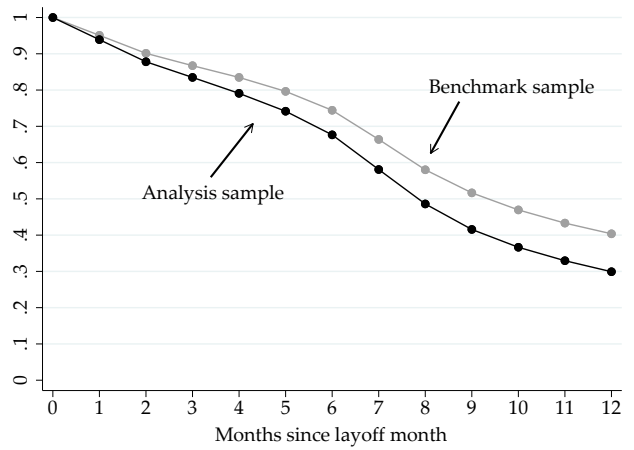

Notes: The figure provides background information on displaced formal workers in our empirical setting and compares our analysis sample to a benchmark sample drawn randomly from the universe of displaced formal workers in São Paulo. Panel (a) displays the average statutory job displacement insurance benefits that workers are eligible for in the two samples. Panels (b)-(d) display the share actually drawing UI benefits, the hazard rate of formal reemployment, and the survival rate without a formal job in each month after layoff, respectively. The samples in panel (b) are restricted to workers laid off in 2011 such that we observe their full UI spell in the UI data (the UI takeup rate is 0.768 and the average UI duration conditional on takeup is 4.23 months in the analysis sample). We show in Appendix Figure A2 that the patterns presented in panels (a), (c), and (d) are very similar when we restrict attention to 2011. 
Figure 3. : Benchmarking our expenditure data

(a) Comparison with survey data by wage deciles

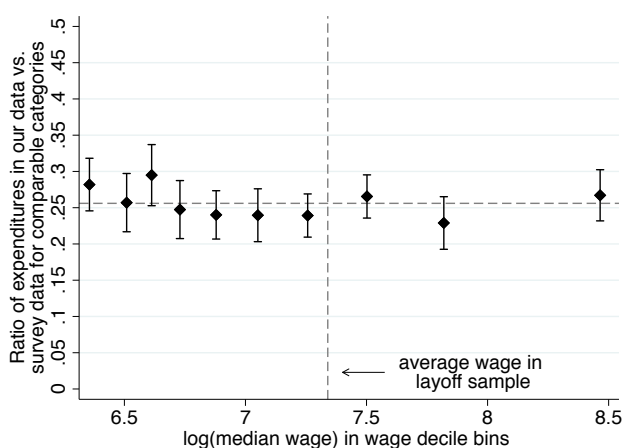

(b) $\Delta$ Wage and $\Delta$ Expenditure in our data

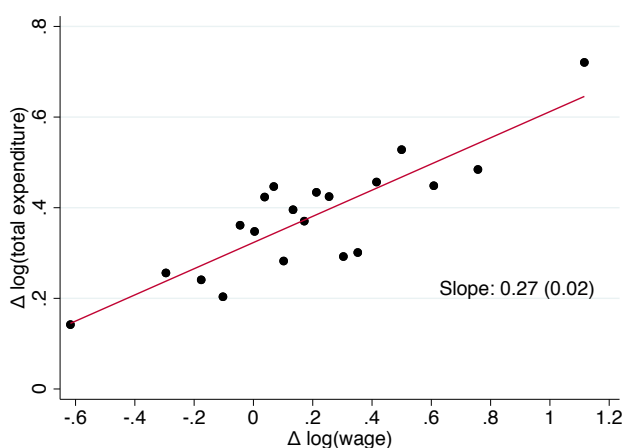

Notes: The figure provides evidence supporting the quality of our de-identified expenditure data. Panel (a) displays the ratio of average expenditures as measured in our data and in the 2009-2010 Survey of Household Expenditures (POF), by wage decile for workers formally employed at the time of the interview (survey data) and on December 31st (our data) in São Paulo (we randomly assign an interview date to formal workers in our data; see Appendix B). Average expenditure levels are estimated for each decile and dataset separately before taking their ratio, reweighing our data to match the distribution in the survey data of demographic characteristics observed in both datasets (age quartiles, dummy variables for being white, having a high school degree, and being female). 95\% confidence intervals are calculated by the delta method. We restrict attention to spending categories that are covered in both datasets (i.e., the purchase of goods). The vertical line indicates the average wage in our analysis sample. The horizontal line indicates the average ratio across wage bins. Panel (b) displays a binscatter of the correlation between $\Delta \log ($ totalexpenditure) and $\Delta \log ($ wage) in our data (using the covariate correction proposed by Cattaneo et al., 2019). We exploit changes in wages for workers who switch firms, regressing $\Delta_{t-1}^{t+1} \log \left(\right.$ expenditure) on $\Delta_{t-1}^{t+1} \log ($ wage $)$ and year fixed effects, where $t$ is the first year in the new job. 
Figure 4. : Expenditure profile around displacement

(a) DD estimates for laid-off workers

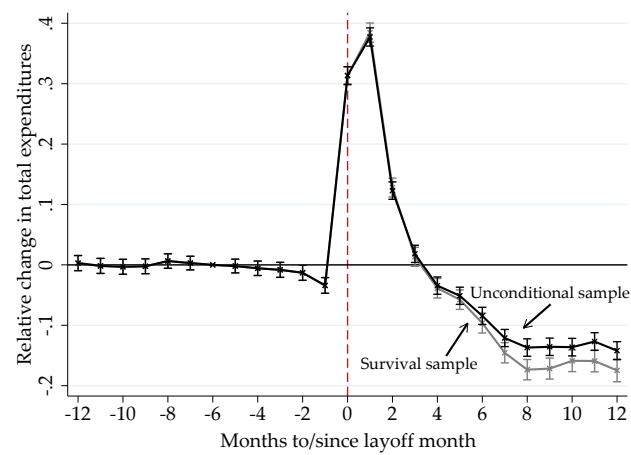

(b) DD estimates for fired workers (unconditional)

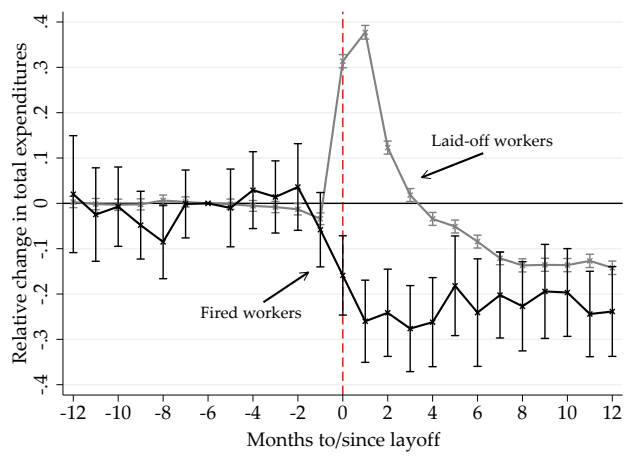

Notes: The figure displays the estimated changes in total expenditures around displacement events. Panel (a) presents DD estimates for laid-off workers (our analysis sample) with their $95 \%$ confidence intervals using the specification in equation (1). The black line in panel (a) displays estimates using the whole treatment and control groups (unconditional sample). The grey line displays estimates restricting the treatment group to displaced workers who remain non-employed in each month after layoff (survival sample; see text). Panel (b) presents similar DD estimates for workers who were fired for cause and were thus not eligible for any job displacement insurance at separation. We plot the DD estimates for laid-off workers in the same graph to facilitate visual comparison; we only display results for the unconditional sample in panel (b), but Appendix Figure A4 displays a similar graph for the survival sample. 
Figure 5. : Expenditure profile around displacement by month of re-remployment

(a) DD estimates, workers reemployed in month 0

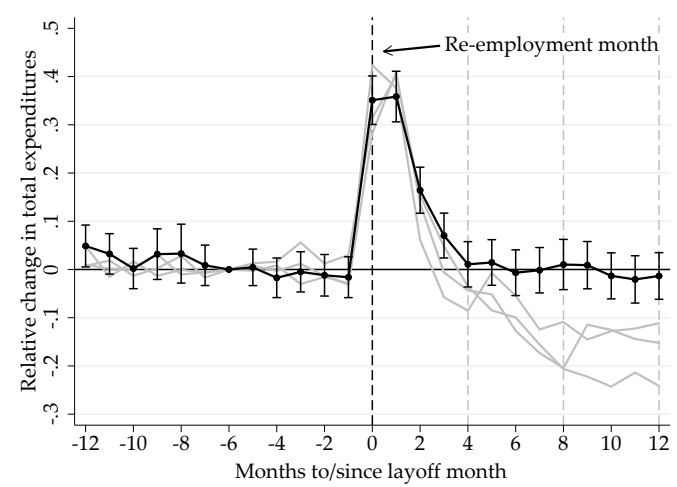

(c) DD estimates, workers reemployed in month 8

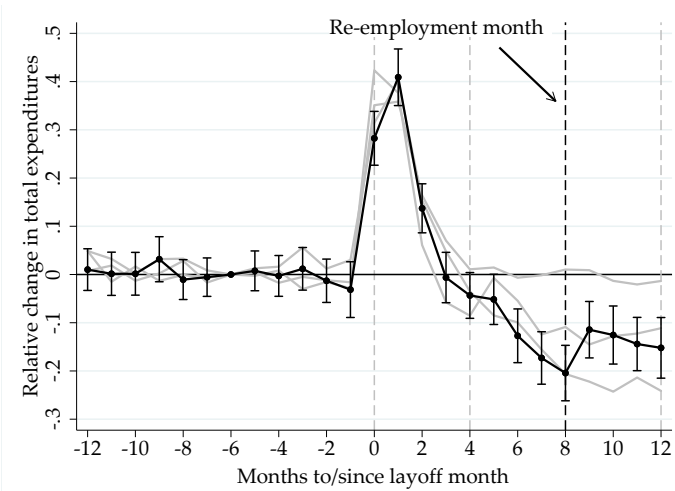

(b) DD estimates, workers reemployed in month 4

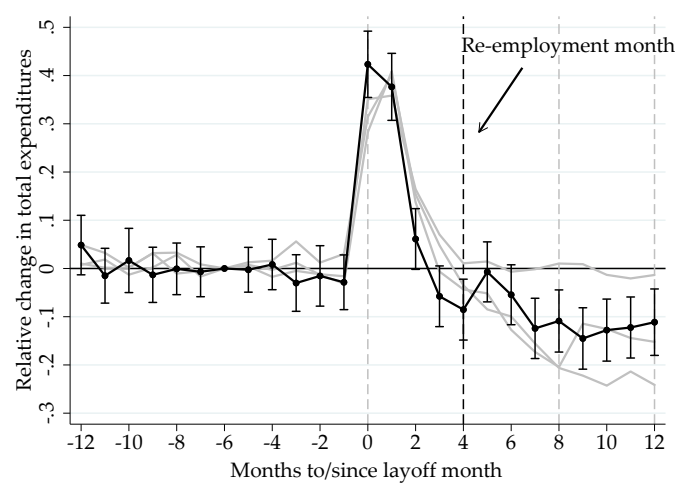

(d) DD estimates, workers reemployed in month 12

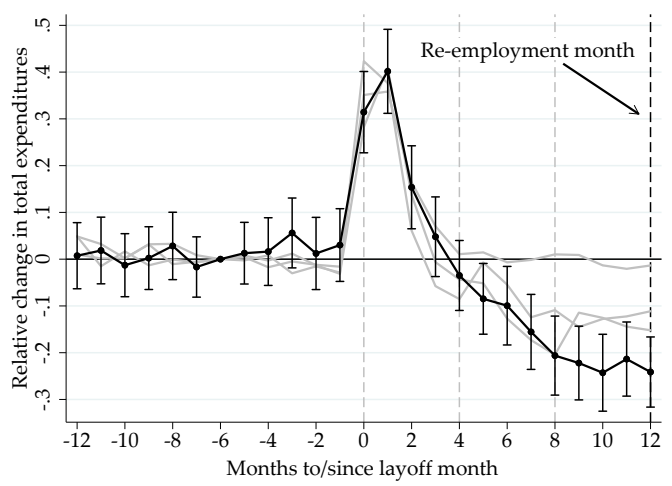

Notes: The figure displays the estimated changes in total expenditures around displacement events, separately for samples of laid-off workers reemployed in different months after layoff. Specifically, panels (a)-(d) present similar DD estimates as in Figure 4 for different (fixed) subsets of the treatment group, namely workers formally reemployed in months $0,4,8$, and 12 after layoff. We display the same estimates in each panel, but we highlight estimates for each subsample in turn along with their $95 \%$ confidence intervals (the vertical lines indicate the month of reemployment for that subsample), while keeping the point estimates for the other subsamples (in light grey) to facilitate comparison. 
Figure 6. : Non-durable expenditure profile around displacement

(a) Composition of spending (before layoff)

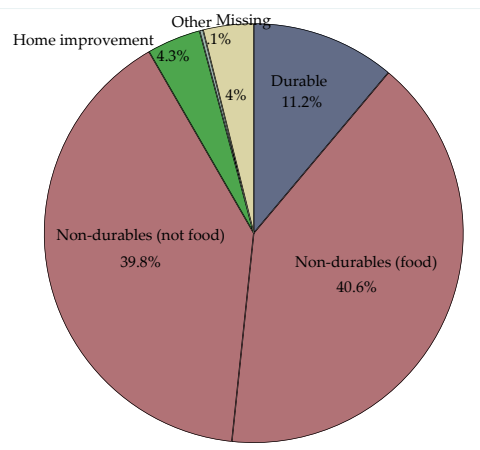

(b) DD estimates for non-durables

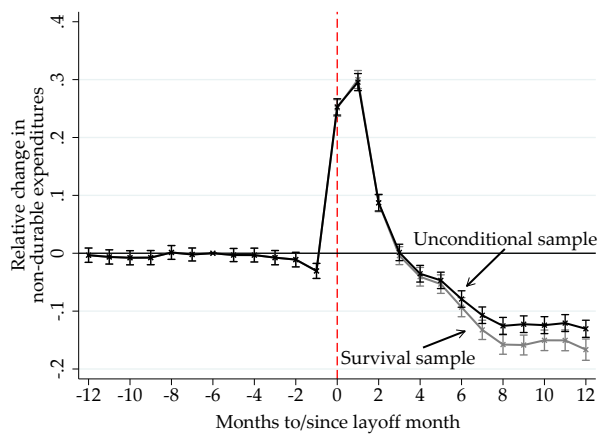

(d) DD estimates for food

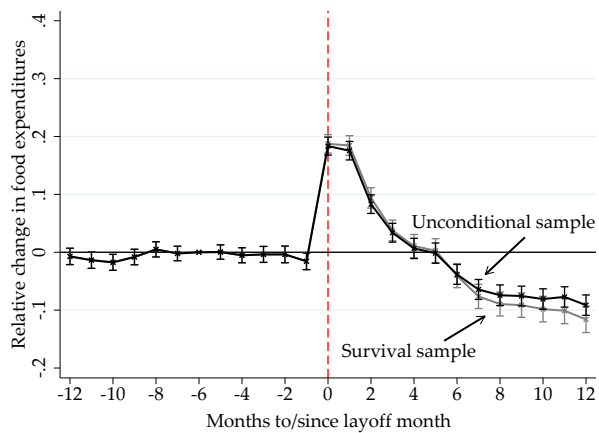

(c) DD estimates for strict non-durables

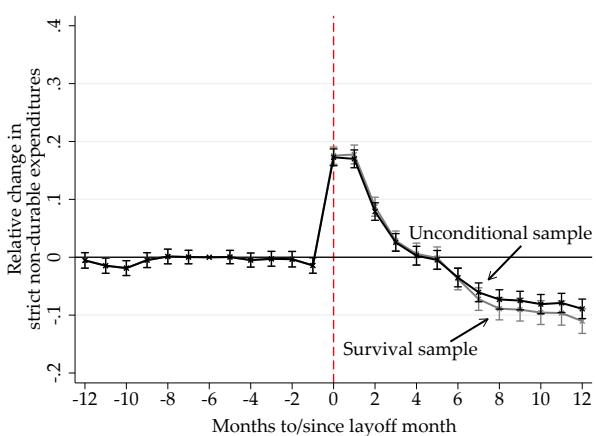

(e) DD estimates for small ticket items

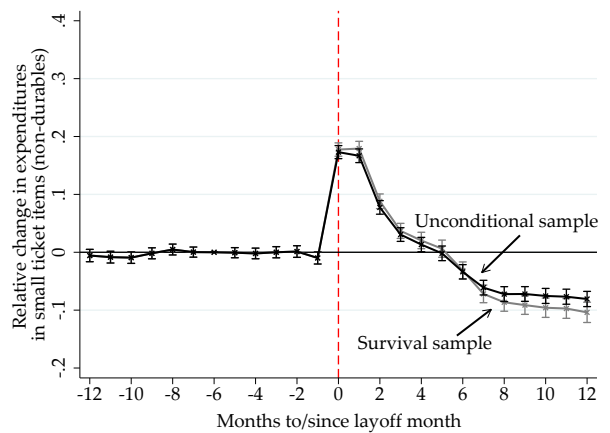

Notes: The figure displays the estimated changes around displacement events for non-durable expenditure categories. Panel (a) displays the composition of expenditures before layoff (average over $k=-12$ to $k=-6$ ) in the treatment group. The main categories are food, other non-durables, and durables. Panel (b) displays similar DD estimates as in Figure 4 a for all non-durables. Panel (c) displays DD estimates for a subset of non-durables that follows Lusardi (1996)'s strict non-durable definition (excluding semi-durables, education and health-related expenditures). Panel (d) displays DD estimates for food expenditures (groceries and food away from home combined). Panel (e) displays DD estimates for small ticket items only within non-durable expenditures, i.e., items costing less than R $\$ 25$ ( US\$12.5). 
Figure 7. : Heterogeneity in non-durable expenditure profiles around displacement by SP amount and UI replacement rate (unconditional sample)

(a) Heterogeneity by SP

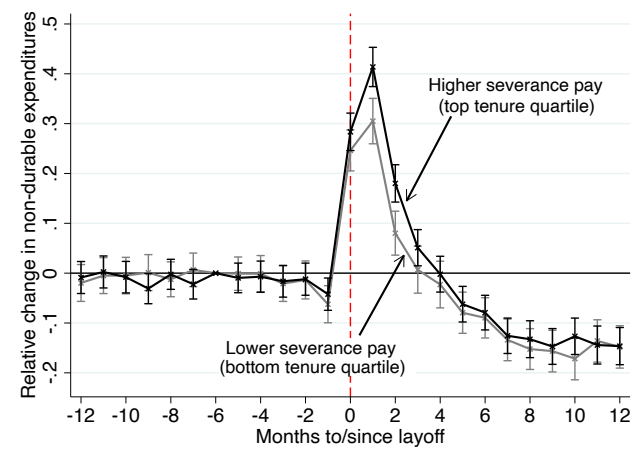

(b) Heterogeneity by UI replacement rate

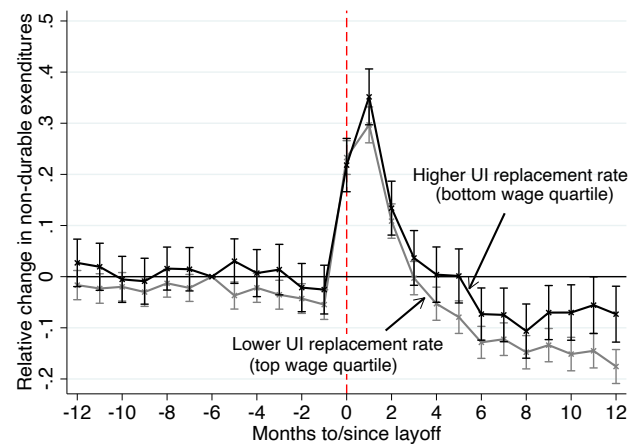

Notes: The figure displays the estimated changes around displacement events for non-durable expenditures for workers eligible for different job displacement insurance benefits. Panel (a) presents DD estimates comparing workers in the bottom and top quartiles of the tenure distribution at layoff. The replacement rate from the total SP amount (SP amount/pre-layoff wage) is an increasing function of job tenure at layoff: on average, it reaches $427 \%$ and $745 \%$ in the bottom and top tenure quartiles, respectively. We also restrict the samples to workers who had more than 24 months of tenure at layoff, such that they were all eligible for the same potential UI duration (see text). Panel (b) presents DD estimates comparing workers in the bottom and top quartiles of the wage distribution at layoff. The UI replacement rate is a decreasing function of the wage prior to layoff: on average, it reaches $83 \%$ and $38 \%$ in the bottom and top wage quartiles, respectively. We use the specification in equation (2), which is similar to the specification in equation (1) but interacting all right-hand-side variables with dummies for each tenure quartile (resp. wage quartile), and controlling flexibly for wages (resp. tenure). 
Figure 8. : Non-durable expenditure profile around UI payday and UI exhaustion

(a) Around UI payday within a month

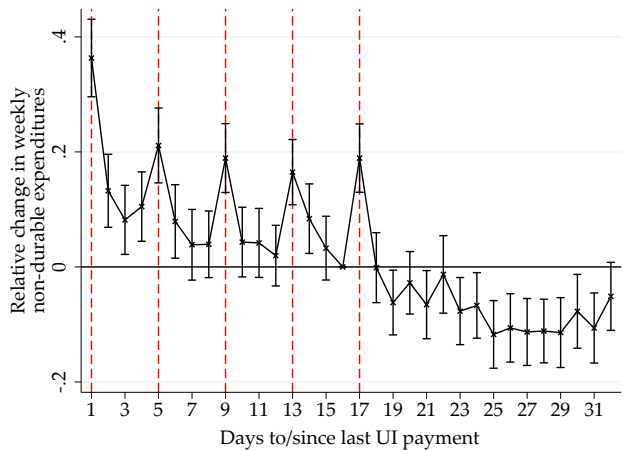

(b) Around the month of UI exhaustion

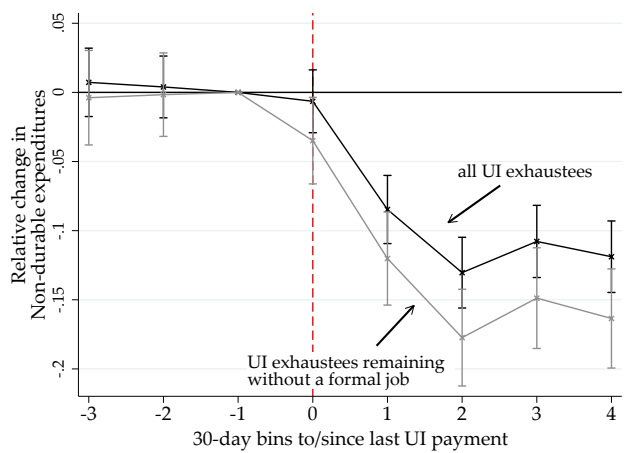

Notes: The figure displays the estimated changes in non-durable expenditures (point estimats and $95 \%$ confidence intervals) for event analyses centered around UI payment dates and UI exhaustion using the specification in equation (1). We restrict attention to the subset of our treatment group for which workers were observed drawing 5 monthly UI payment, the maximum potential UI duration (UI exhaustees) and we assign "placebo" UI payment dates to workers in our control group. Panel (a) investigates how nondurable expenditures change around UI payment dates within a month. Our window of analysis starts at the first UI payment date. We then divide the time between two payment dates into four periods: three 7-day periods spanning the first 21 days since a UI payment (the first period includes the payment date) and a fourth period including the remaining days until the next UI payment (vertical lines indicate 7-day periods starting with a UI payment date). To investigate how consumer spending also evolves after UI exhaustion, we construct comparable time periods after the last UI payment (see text for details). Panel (b) investigates how non-durable expenditures change around UI exhaustion by aggregating the data in panel (a) by 30-day periods centered around UI exhaustion (the vertical line indicates the 30-day period starting with the last UI payment date). We plot estimates using all UI exhaustees in the treatment group as in panel (a), and restricting attention to those who remain without a job for at least 150 days after the last UI payment date (the end of our analysis window). 
Figure 9. : Model fit for the consumption profile

(a) Benchmark: $\delta=0.995, \beta=1$

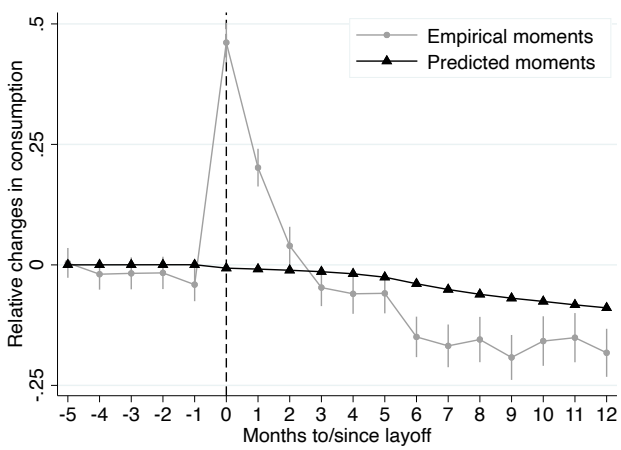

(c) Naïve $\beta \delta: \delta=0.995, \widehat{\beta}=0.44$

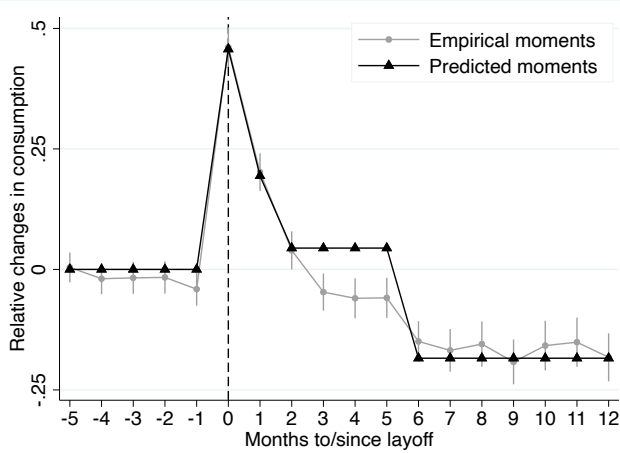

(b) Myopia: $\widehat{\delta}=0.69, \beta=1$

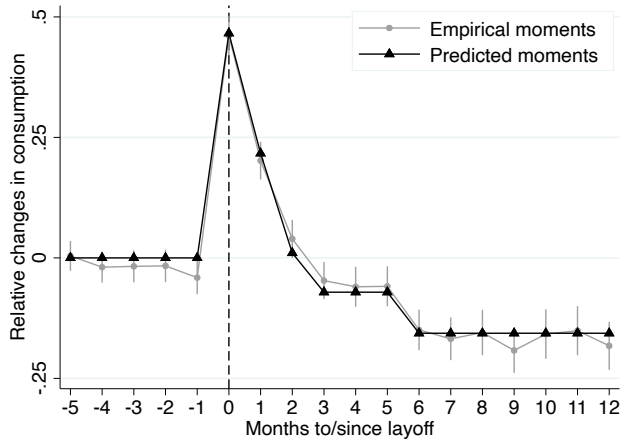

(d) Sophisticated $\beta \delta: \delta=0.995, \widehat{\beta}=0.70$

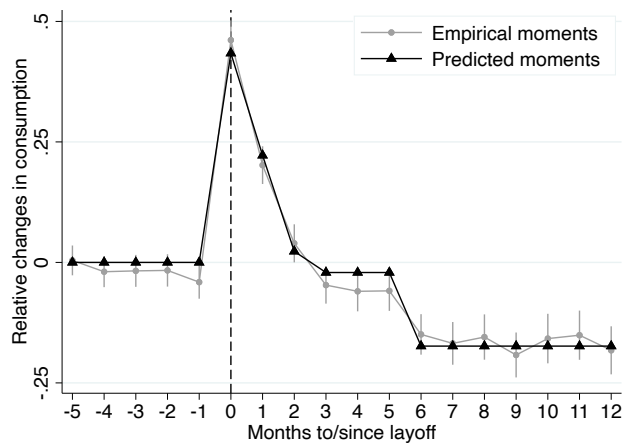

Notes: The figure displays the fit of the four models in Table 2 with respect to the target empirical moments capturing key consumption patterns in our data. The grey lines display the target empirical moments in each panel. The black lines display the predicted moments for the estimated models. 
Figure 10. : Counterfactual policies using the sophisticated present-bias model

(a) Consumption profile

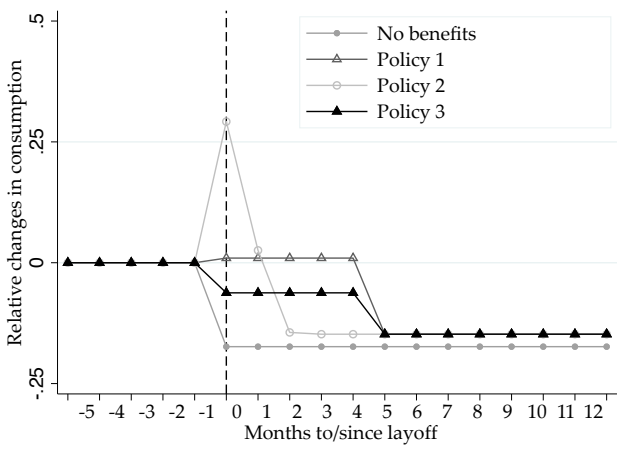

(b) Hazard rates of reemployment

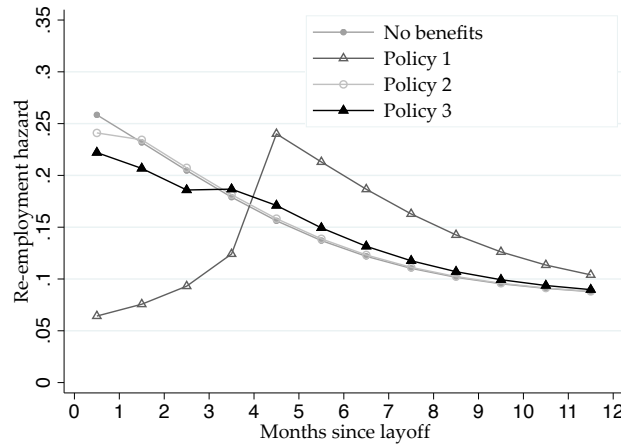

$\Delta$ Welfare $\quad \Delta$ Welfare $\Delta$ Welfare

Insurance Value Incentive effect Additional

\begin{tabular}{|c|c|c|c|c|}
\hline & & [1] & {$[2]$} & [3] \\
\hline$\triangle$ & Policy 1: 5 months of UI & 0.22 & -0.37 & -0.37 \\
\hline 0 & Policy 2: equivalent SP paid lump-sum at layoff & 0.05 & 0.00 & -0.04 \\
\hline$\simeq$ & Policy 3: equivalent SP paid in 5 monthly installme & 0.15 & 0.00 & -0.11 \\
\hline
\end{tabular}

Notes: The figure displays the predicted consumption profile and hazard rates of reemployment for counterfactual job displacement insurance designs using the sophisticated present-bias model in column (4) of Table 2. In both panels, we first display the predictions of the model with no job displacement insurance benefits. Then, we consider (i) a UI program paying the same average benefit level as in the estimation sample for a potential UI duration of 5 months after layoff; (ii) a SP program paid in a lump-sum fashion at layoff; and (iii) a SP program paying the same amount in 5 monthly installments. The three programs are designed such that their mechanical cost - their cost assuming the same search efforts as with no benefits - is the same, and a per-period tax is levied prior to layoff to pay for that cost. The figure also displays the expected welfare effect of each of these programs, compared to the nobenefits case, based on simulating 1500 employment histories (see discussion in Section IV.G). Column (1) displays the insurance value of these policies, i.e., the standard welfare effect from their consumptionsmoothing gains. Column (2) displays the incentive effect of these policies, i.e., the standard measure of efficiency loss from behavioral responses (changes in search efforts) to such programs in the UI literature. It is measured by their fiscal externality, i.e., the ratio of the increase in programs' cost once workers adjust search efforts to their cost absent behavioral responses. Finally, column (3) displays any additional change in workers' own welfare from adjusting search efforts. All values in the table are expressed in $\$ 1$ per $\$ 1$ spent on target beneficiaries; a negative value corresponds to a welfare loss. 